\title{
Reaction of spironaphthoxazine with acid
}

\section{Hiromasa Nishikiori,* Suguru Shimamura, Tsuneo Fujii}

Department of Environmental Science and Technology, Faculty of Engineering,

Shinshu University, 4-17-1 Wakasato, Nagano 380-8553, Japan

Corresponding author: Hiromasa Nishikiori

Tel: +81-26-269-5536

Fax: +81-26-269-5550

E-mail: nishiki@shinshu-u.ac.jp

Department of Environmental Science and Technology, Faculty of Engineering,

Shinshu University, Wakasato, Nagano 380-8553, Japan 


\section{Abstract}

The reaction of spironaphthoxazine (SNO) with acid in ethanol was investigated by spectroscopic analyses SNO was protonated and then transformed into a complex in an acidic ethanol solution in the dark. It is presumed that the complex contains a hydrated proton and its structure is similar to that of the metal complex of a merocyanine-type isomer photoderived from SNO based on its UV-vis absorption and fluorescence spectra. The complex dissociated into SNO by adding base. The complex was further changed under acidic conditions after a long time. Highly concentrated acid decomposed SNO to an indoline compound having a carboxyl group and 1-amino-2-naphthol, which was revealed by fluorescence, IR, and GC-MS analyses. These reaction processes were promoted by UV irradiation.

Keywords: Spironaphthoxazine; Acid; Protonation; Complex; Fluorescence 


\section{Introduction}

Organic dye molecules generally have high absorption efficiencies and some of them exhibit a specific color compared to inorganic materials. A high number of organic dye molecules are not required for the coloration of materials, which allow modification of their photochemical properties and add specific photo-functions without a change in the material properties. The coloration and photoemission are interesting photochemical phenomena applicable to the photo-function. Many promising organic compounds exhibiting a photochromic behavior have been found and widely investigated in various fields [1]. Photochromism is an important phenomenon that provides a photochemical technique for the development of electronic devices such as photo-quantum switching and memory [1-6]. The photochromic phenomena originate not only from the photo-isomerization of molecules, but also from the photoinduced metal chelation of organic ligands [7-13]. The photoreaction and photochemical properties of the molecules need to be controlled in order to perform a fast and effective photochromism. Therefore, it is important to study the reaction mechanism of such organic molecules in solutions under various conditions.

Spirooxazines (SOs) exhibit the well-known photochromic reaction of the photoinduced interconversion between the original colorless form and the colored merocyanine (MC) form [3,6]. The MC is easily coordinated with specific metal ions, e.g., $\mathrm{Zn}^{2+}$, in solution and 
forms both fluorescent and non-fluorescent $\mathrm{MC}^{-\mathrm{M}^{\mathrm{n}+}}$ complexes; the fluorescent complexes are stable to heat and visible light while the non-fluorescent complexes are unstable $[7,8]$.

We previously reported the details of the fluorescence and excitation spectra of spironaphthoxazine (SNO) in various solvents [14]. Two types of fluorescent intermediate species $\left(\mathrm{X}_{\mathrm{s}}\right.$ and $\mathrm{X}_{\mathrm{h}}$ ) occur between $\mathrm{SNO}$ and $\mathrm{MC}$ by cleavage of the spiro $\mathrm{C}-\mathrm{O}$ bond, as shown by Scheme $1[15-18]$. The fluorescence processes of SNO and the intermediate species are shown in Scheme 2. The intermediate species can be also regard as one of the $\mathrm{MC}$ isomers, i.e., the $\mathrm{CCC}$ (cis-cis-cis) or TCC (trans-cis-cis) form for the $\mathrm{C}=\mathrm{C}-\mathrm{N}=\mathrm{C}$ bond [19,20]. MC, we call it in this study, is assigned to TTC (trans-trans-cis) form. In low-polar solvents, such as benzene, upon the excitation of SNO $\left(E_{1}\right)$, the $390-\mathrm{nm}$ fluorescence $\left(\mathrm{F}_{1}\right)$ is normally emitted from its excited state $\left(\mathrm{SNO}^{*}\right)$. In aprotic polar solvents, such as acetonitrile, some of the SNO molecules are transformed into a non-planar, strongly solvated species $\left(\mathrm{X}_{\mathrm{s}}\right)$. Such aprotic polar molecules strongly interact with the C and $\mathrm{O}$ atoms of the spiro $\mathrm{C}-\mathrm{O}$ moiety and distort the spiro structure. The transition from species $\mathrm{X}_{\mathrm{s}}$ to $\mathrm{X}_{\mathrm{s}}{ }^{*}\left(\mathrm{E}_{2}\right)$ is followed by a 450 -nm fluorescent emission $\left(\mathrm{F}_{2}\right)$. In protic polar solvents, such as ethanol and water, some of the SNO molecules are normally excited to SNO* $\left(\mathrm{E}_{1}\right)$ to produce the hydrogen-bonded species $\left(\mathrm{X}_{\mathrm{h}}{ }^{*}\right)$ by the $\mathrm{C}-\mathrm{O}$ bond breakage in the excited states, followed by the $430-\mathrm{nm}$ fluorescent transition to $X_{h}\left(F_{3}\right)$. A protic polar 
molecule more strongly bonds to the $\mathrm{O}$ atom of the spiro $\mathrm{C}-\mathrm{O}$ moiety and weakens the $\mathrm{C}-\mathrm{O}$ bond. The $\mathrm{X}_{\mathrm{h}}$ species was immediately transformed into SNO or MC in the ground state because it was unstable at room temperature. Scheme 2 shows the two extreme fluorescence processes of the intermediate species. Actually, the two process can occur in polar solvents. The fluorescence of the MC- $\mathrm{Zn}^{2+}$ complex is observed at around $540 \mathrm{~nm}$ by UV irradiation of SNO in aprotic polar solvents, such as acetone and acetonitrile, in the presence of $\mathrm{Zn}^{2+}[7,8,21,22]$. The $\mathrm{MC}-\mathrm{Zn}^{2+}$ complex was not observed in ethanol because the MC form was stabilized by hydrogen bonding to the solvent molecules [23]. On the other hand, a small number of protons assisted the $\mathrm{MC}-\mathrm{Al}^{3+}$ complex formation in the ethanol solution containing $\mathrm{Al}^{3+}[24]$.

(Schemes 1 and 2)

In our previous studies, we observed the fluorescence photochromic behavior, that is, the photoinduced interconversion between $\mathrm{X}_{\mathrm{s}}$ and the $\mathrm{MC}-\mathrm{Zn}^{2+}$ complex in the hydrophobic interlayers of montmorillonite clay modified by organic surfactants [15] and in a xerogel prepared from silicon alkoxide [16-18]. The xerogel system also contained the MC-SiOH complex, like the $\mathrm{MC}-\mathrm{Zn}^{2+}$, because there were many acidic SiOH groups on the surface of the gel pores in which the organic molecules were encapsulated [16-18,25-28]. The complex formation is expected to depend on the type of metal ions involving a specific 
electron affinity $[18,24]$. MC can interact not only with the metal ions, but also with the protons on the silica gel surface.

In this study, we observed the reactions of $\mathrm{SNO}$ in an ethanol solution containing hydrochloric acid in order to reveal the interaction between SNO and the protons. The dark and photochemical reaction processes were investigated by measuring the UV-vis absorption and fluorescence spectra as a function of time.

\section{Experimental}

SNO was purchased from Tokyo Chemical Industry and used without further purification.

Ethanol (99.5\%, S grade), aluminum chloride hexahydrate (S grade), hydrochloric acid (S grade), sodium hydroxide (S grade), and 1-amino-2-naphthol hydrochloride (reagent grade) were purchased from Wako Pure Chemicals and used without further purification.

An SNO ethanol solution and an aluminum chloride ethanol solution were prepared and adjusted to $9.6 \times 10^{-4}$ and $3.2 \times 10^{-4} \mathrm{~mol} \mathrm{dm}^{-3}$ concentrations, respectively. The SNO ethanol solutions containing aluminum chloride were prepared by mixing $5.0 \mathrm{~cm}^{-3}$ of the SNO solution and $5.0 \mathrm{~cm}^{-3}$ of the aluminum chloride solution. Hydrochloric acid was adjusted to $3.2 \times 10^{-4}$ and $3.2 \times 10^{-2} \mathrm{~mol} \mathrm{dm}^{-3}$ concentrations. The acidic SNO ethanol solutions were prepared by mixing $5.0 \mathrm{~cm}^{-3}$ of the SNO solution and $5.0 \mathrm{~cm}^{-3}$ of the 
hydrochloric acid. The concentration of SNO was $4.8 \times 10^{-4} \mathrm{~mol} \mathrm{dm}^{-3}$ in all the solutions. A 1-amino-2-naphthol ethanol solution was also prepared in which its concentration was $4.8 \times$ $10^{-4} \mathrm{~mol} \mathrm{dm}{ }^{-3}$. The UV-vis absorption spectra were measured as a function of time in the dark and during UV irradiation at $298 \mathrm{~K}$ using a Shimadzu UV-2500 spectrophotometer. The fluorescence and excitation spectra were also measured in the same way using a Shimadzu RF-5300 fluorescence spectrophotometer. The UV $\left(350 \pm 10 \mathrm{~nm}, 20 \mathrm{~mW} \mathrm{~cm}{ }^{-2}\right)$ irradiation was conducted using a Shimazdu RF-5000 fluorescence spectrophotometer with a 150-W Xe short arc lamp (Ushio UXL-155) in order to study the photoreaction.

The UV-vis absorption, fluorescence, and excitation spectra of the acidic SNO solution allowed to react for $48 \mathrm{~h}$ during the UV irradiation were observed before and after adding the sodium hydroxide solution until the $\mathrm{pH}$ value reached 12 .

Gas chromatography-mass spectrometry (GC-MS) of the acidic SNO solution allowed to react for $288 \mathrm{~h}$ during the UV irradiation, labeled Solution A, was performed using a gas chromatograph-mass spectrometer (Shimadzu GCMS-QP5000). The IR spectrum of the powder sample obtained by evaporating Solution A to dryness was measured using an FTIR spectrophotometer (Shimazdu IRPrestige-21).

\section{Results and discussion}




\subsection{Reaction of SNO with aluminum ion}

In the ethanol solution, hydrogen bonding induced the isomerization from SNO to $\mathrm{MC}$ in the ground state via the unstable $X_{h}[14]$. The $X_{h}$ species was immediately transformed into SNO or MC. However, the equilibrium constant of the reaction from SNO to MC is low at around room temperature. The concentration of $\mathrm{MC}$ was very low under the present condition. Fig. 1 shows the change in the UV-vis absorption spectrum of the SNO ethanol solution containing $\mathrm{Al}^{3+}$ during the $\mathrm{UV}$ irradiation. The molar ratio of $\mathrm{SNO}$ to $\mathrm{Al}^{3+}$ was $3 / 1$. The spectral band having peaks at around 300,320 and $350 \mathrm{~nm}$ and a shoulder at around 370 $\mathrm{nm}$ originates from the naphthoxazine ring moiety of SNO [29-31]. In addition, the spectrum observed just after the preparation (at time 0) exhibited a band at $530 \mathrm{~nm}$ assigned to the species protonated at the naphtholate part of the $\mathrm{MC}\left(\mathrm{MCH}^{+}\right)[24,32,33]$. This assignment was confirmed by the spectral change in the SNO ethanol solution containing hydrochloric acid as shown below. The proton assisted in the $\mathrm{C}-\mathrm{O}$ bond cleavage and ring opening of the SNO. There is the possible formation of the protonated $\mathrm{SNO}\left(\mathrm{SNOH}^{+}\right)$and its fast thermal isomerization to $\mathrm{MCH}^{+}$.

(Fig. 1)

The band intensity at $530 \mathrm{~nm}$ increased and then decreased. With this decrease, a band at $450 \mathrm{~nm}$ became evident due to the aluminum-chelation of MC. Most of the aluminum ions 
are expected to be solvated in the ethanol solution and form hydrogen-bonded complexes such as $\left[\mathrm{Al}(\mathrm{EtOH})_{4}\right]^{3+}[34]$. The proton was provided by the reaction of $\mathrm{Al}^{3+}$ with a slight amount of water contained in the ethanol solvent, and then some aluminum ions formed $\left[\mathrm{Al}(\mathrm{OH})(\mathrm{EtOH})_{3}\right]^{2+}[35]$. The protonated species was slowly transformed into the

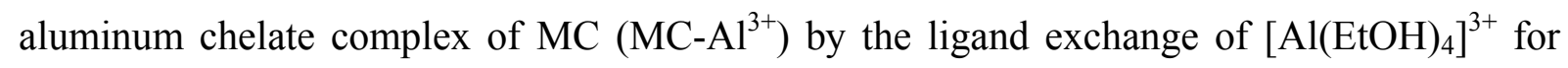
MC. Under this condition, the reaction rates were faster and the amounts of products were greater than in the dark although the spectral peak positions and the patterns of increase and decrease in their intensities were similar to those in the dark. It was previously confirmed that SNO directly formed the $\mathrm{MC}-\mathrm{Al}^{3+}$ complex without forming the protonated species during the UV irradiation [24]. The protonation and aluminum chelation of SNO easily proceeded under the present conditions. The chelation was assisted by the addition reaction of protons and subsequent ring-opening.

The fluorescence and excitation spectra observed as a function of the UV irradiation time are shown in Fig. 2. Just after the preparation, the peaks of the fluorescence and excitation spectra observed at $425 \mathrm{~nm}$ and 295 and $357 \mathrm{~nm}$, respectively, were assigned to $X_{\mathrm{h}}$. The fluorescence lifetime was reported to be $1.1 \mathrm{~ns}$ in methanol [36]. The reference stated that SNO was transformed into MC via an excited state of the intermediate species, which was non-fluorescent. The solvent-stabilized fluorescent state was formed from the high-energy 
excited state of the intermediate species by the vibronic relaxation. The excited state lifetime of the solvent-stabilized fluorescent $\mathrm{X}_{\mathrm{h}}{ }^{*}$ was determined to be ca. $1 \mathrm{~ns}$, whereas that of the non-fluorescent $\mathrm{X}_{\mathrm{h}}{ }^{*}$ decayed and formed $\mathrm{MC}$ within a few ps [36]. The excitation band was shifted to the longer wavelength side with an increase in the UV irradiation time even though the related fluorescence band had slightly changed. The set of fluorescence and excitation bands observed after the UV irradiation are similar to those observed in aprotic polar solvents, indicating the existence of the certain ground-state species [14]. Therefore, it is suggested that $\mathrm{X}_{h}$ was transformed into the protonated $\mathrm{X}_{\mathrm{h}}$ species $\left(\mathrm{X}_{\mathrm{h}} \mathrm{H}^{+}\right)$, i.e., the certain intermediate state between $\mathrm{SNOH}^{+}$and $\mathrm{MCH}^{+}$in the ground state was allowed by the interaction with a proton. This change was not reflected in the absorption spectra because the amounts of such intermediate protonated species were much lower than that of SNO. The peaks of the fluorescence and excitation spectra at $540 \mathrm{~nm}$ and $462 \mathrm{~nm}$, respectively, assigned to $\mathrm{MC}-\mathrm{Al}^{3+}$, were observed after the UV irradiation and their intensities increased with an increase in the irradiation time. No fluorescence was assigned to $\mathrm{MCH}^{+}$because it is a non-fluorescent species.

(Fig. 2)

\subsection{Reaction of SNO with acid}

Changes in the UV-vis absorption spectra were investigated in order to examine the acidic 
influence on the SNO behavior in the ethanol solutions. The band assigned to $\mathrm{MCH}^{+}$was observed at $530 \mathrm{~nm}$ and its intensity increased with time in the acidic SNO ethanol solution in which the molar ratio of $\mathrm{SNO}$ to $\mathrm{H}^{+}$was $3 / 1$ as previously reported [24]. Fig. 3 shows the change in the UV-vis absorption spectrum of the SNO ethanol solution containing hydrochloric acid in the dark and during the UV irradiation. The molar ratio of SNO to $\mathrm{H}^{+}$ was 3/100. The spectral change was very similar to that of the solution containing $\mathrm{Al}^{3+}$. The spectrum observed at 0 exhibited a band at $530 \mathrm{~nm}$ assigned to $\mathrm{MCH}^{+}$. The band intensity at $530 \mathrm{~nm}$ increased and then decreased. The $\mathrm{MCH}^{+}$band intensity was much higher than that observed in the solution containing $\mathrm{Al}^{3+}$ due to a higher number of protons. Furthermore, the maximum $\mathrm{MCH}^{+}$band intensity observed during the $\mathrm{UV}$ irradiation was much greater than that observed in the dark. The band intensity at $450 \mathrm{~nm}$ increased with the 530-nm band decrease. This band can be assigned to a complex of MC with a proton and water molecule, $\mathrm{MC}-\mathrm{H}_{3} \mathrm{O}^{+}$, having a structure similar to the metal chelate complex of $\mathrm{MC}$ $\left(\mathrm{MC}-\mathrm{M}^{\mathrm{n}+}\right) . \quad$ The structure of this complex is presumed to be very similar to the MC-SiOH complex observed in the silica xerogel [16-18].

The time course of the absorbance values for the peaks of $\mathrm{MCH}^{+}$and $\mathrm{MC}-\mathrm{H}_{3} \mathrm{O}^{+}$in Fig. 3 is plotted in Fig. 4. The reactions of SNO with acid are expressed by the following equations: 


$$
\begin{aligned}
& \mathrm{SNO}+\mathrm{H}^{+} \stackrel{k_{1}}{\rightarrow} \mathrm{MCH}^{+} \\
& \mathrm{MCH}^{+}+\mathrm{H}_{2} \mathrm{O} \stackrel{k_{2}}{\rightarrow} \mathrm{MC}-\mathrm{H}_{3} \mathrm{O}^{+} \\
& \mathrm{SNO}+\mathrm{H}^{+}+\mathrm{H}_{2} \mathrm{O} \stackrel{k_{3}}{\rightarrow} \mathrm{MC}-\mathrm{H}_{3} \mathrm{O}^{+} \\
& \mathrm{MC}-\mathrm{H}_{3} \mathrm{O}^{+} \stackrel{k_{4}}{\rightarrow} \text { Products }
\end{aligned}
$$

Reaction (3) in which SNO photochemically forms $\mathrm{MC}-\mathrm{H}_{3} \mathrm{O}^{+}$was suggested to be similar to the $\mathrm{MC}-\mathrm{Al}^{3+}$ formation as shown in a previous study [24]. Reaction (4) should be considered because the other product resulted from $\mathrm{MC}-\mathrm{H}_{3} \mathrm{O}^{+}$as stated below. The reaction rate constants of these four reactions, $k_{1}, k_{2}, k_{3}$, and $k_{4}$, were estimated by the first order analysis of the time course of the absorbance values at the main peaks, 450 and $530 \mathrm{~nm}$, as shown in Table 1. The concentration of $\mathrm{H}^{+}$is regarded as being much higher than that of SNO. The analysis determined the molar extinction coefficient values for the main peaks of each species obtained in a previous study [24]. The molar extinction coefficient for

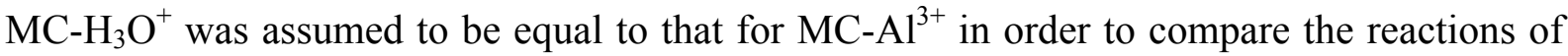
the solution in the dark and during UV irradiation because the structures of their $\pi$ conjugated systems are similar to each other.

(Fig. 4 and Table 1)

The UV irradiation promoted all the reactions by comparison between the reaction rate constants in the dark and during UV irradiation. The constants observed during the UV 
irradiation were 2-6 times higher than those observed in the dark. The changes in the concentration of each species and in the number of absorbed photons were complicated as the reaction proceeded. The rate constants, which were not strict, but apparent values, were clearly increased by the UV irradiation. With respect to reaction (1), the photoisomerization from SNO to $\mathrm{MC}$ induced the forming of $\mathrm{MCH}^{+}$because the quantum yield of the photoisomerization is reported to be a certain value, $0.2-0.4[37,38]$. With respect to reaction (2), $\mathrm{MCH}^{+}$absorbs some UV light, which can thermally induce the MC- $\mathrm{H}_{3} \mathrm{O}^{+}$formation to some extent after the internal conversion because this reaction is suggested to be a ground state process [24]. The constants for the photochemical process of the $\mathrm{MC}-\mathrm{H}_{3} \mathrm{O}^{+}$formation, $k_{3}$, during $\mathrm{UV}$ irradiation were not significantly higher than those of the other processes. This is because the steady state UV irradiation also promoted the dissociation of $\mathrm{MC}-\mathrm{H}_{3} \mathrm{O}^{+}$to form $\mathrm{MCH}^{+}$and consequently decreased the apparent reaction constants of the $\mathrm{MC}-\mathrm{H}_{3} \mathrm{O}^{+}$formation.

The changes in the fluorescence and excitation spectra are shown in Fig. 5. These spectra clearly coincided with those observed in the SNO ethanol solution containing $\mathrm{Al}^{3+}$ during the UV irradiation for at least a few hours. The fluorescence band at around $425 \mathrm{~nm}$ then shifted to the longer wavelength side and a new excitation band at $333 \mathrm{~nm}$ became evident, indicating the production of new species as explained below. 


\section{(Fig. 5)}

The relationships between the absorbance and fluorescence intensities of the $\mathrm{MC}-\mathrm{Al}^{3+}$ and MC- $\mathrm{H}_{3} \mathrm{O}^{+}$complexes were evaluated in order to distinguish their fluorescence properties. The fluorescence intensity values at $540 \mathrm{~nm}$ for the solutions containing $\mathrm{SNO}$ and $\mathrm{Al}^{3+}$ $\left(\mathrm{SNO} / \mathrm{Al}^{3+}=3 / 1\right)$ and $\mathrm{SNO}$ and $\mathrm{H}^{+}\left(\mathrm{SNO} / \mathrm{H}^{+}=3 / 100\right)$ are plotted versus the related absorbance values in Fig. 6. The fluorescence quenching due to the self-absorption by the $\mathrm{MCH}^{+}$species can be negligible under the present conditions. The slope for the SNO- $\mathrm{Al}^{3+}$ system was ca. five times greater than that for the $\mathrm{SNO}-\mathrm{H}^{+}$system, indicating that the fluorescence quantum yield of $\mathrm{MC}-\mathrm{Al}^{3+}$ is higher than that of $\mathrm{MC}^{-} \mathrm{H}_{3} \mathrm{O}^{+}$. This is a result similar to that observed in the sol-gel reaction system of silicon alkoxide, i.e., the fluorescence quantum yield of MC- $\mathrm{M}^{\mathrm{n}+}$ was higher than that of MC-SiOH and depended on the metal ion [18]. The fluorescence process of the metal complex depends on the electron affinity of the metal ion because the metal ion occupies the unshared electron pair on the imine $\mathrm{N}$ which quenches the iminonaphtholate fluorescence [8].

(Fig. 6)

$\mathrm{MCH}^{+}$rapidly returned to SNO within 1 min when neutralized. The rate constant of this process was estimated to be $>5 \times 10^{-2} \mathrm{~s}^{-1}$. Also, the $\mathrm{MC}^{-} \mathrm{H}_{3} \mathrm{O}^{+}$complex can be dissociated by adding base. $\mathrm{MC}-\mathrm{H}_{3} \mathrm{O}^{+}$was gradually dissociated and reproduced $\mathrm{SNO}$ when 
neutralized with the rate constant $1.45 \times 10^{-4} \mathrm{~s}^{-1}$. The reverse processes of reactions (2) and (3), which were much faster than the regular processes, cannot be distinguished due to the very fast reverse process of reaction (1). Fig. S1 shows the UV-vis absorption, fluorescence, and excitation spectra of the solution allowed to react for $48 \mathrm{~h}$ in the dark observed before and after adding the sodium hydroxide solution. The absorption band due to $\mathrm{MCH}^{+}$and $\mathrm{MC}-\mathrm{H}_{3} \mathrm{O}^{+}$disappeared within $1 \mathrm{~min}$ and the absorbance due to SNO increased by adding base until the $\mathrm{pH}$ value reached 12 . With this behavior, the fluorescence and excitation bands assigned to $\mathrm{MC}-\mathrm{H}_{3} \mathrm{O}^{+}$decreased and those assigned to $\mathrm{X}_{\mathrm{h}}$ increased. The spectral red-shift compared to the original $\mathrm{X}_{\mathrm{h}}$ spectra is due to the solvent effect by adding an aqueous sodium hydroxide solution. The dissociation of $\mathrm{MC}-\mathrm{H}_{3} \mathrm{O}^{+}$was confirmed to occur by adding base.

\subsection{Decomposition of SNO}

The fluorescence and excitation spectra of the SNO ethanol solution with hydrochloric acid, which was allowed to react for $24 \mathrm{~h}$, is compared to those of 1-amino-2-naphthol in Fig. 7. In the acidic SNO ethanol solution, the fluorescence peak was observed at $360 \mathrm{~nm}$ upon excitation at $287 \mathrm{~nm}$ and the excitation peaks were observed at 266, 276, 287, and $333 \mathrm{~nm}$ when monitoring the $365-\mathrm{nm}$ fluorescence. In addition, the peaks of the fluorescence spectra were also observed at around $440 \mathrm{~nm}$, which were red-shifted compared to the 
425-nm peak assigned to $X_{\mathrm{h}}$. The related excitation band was also observed at 350-400 nm when monitoring the $445-\mathrm{nm}$ fluorescence. The 540-nm fluorescence peak is due to MC- $\mathrm{H}_{3} \mathrm{O}^{+} \quad$ These bands, except for the 540-nm fluorescence, are very similar to those of 1-amino-2-naphthol, which exhibits fluorescence and excitation peaks at $357 \mathrm{~nm}$ and at 263, 276, 286, and $333 \mathrm{~nm}$, respectively, assigned to the neutral species of 1-amino-2-naphthol $[39,40]$. Furthermore, the fluorescence peak at around $450 \mathrm{~nm}$ and the related excitation band at 350-400 $\mathrm{nm}$ are assigned to the anion species. These results indicated that SNO was decomposed and produced 1-amino-2-naphthol. In addition to this, indoline compounds are also expected to be produced.

(Fig. 7)

The GC-MS and FTIR analyses were conducted in order to confirm the decomposition of SNO and determination of the products. These results are shown in Figs. S2 and S3, respectively. Three chromatogram peaks were observed and they were assigned to SNO or MC, 1-amino-2-naphthol, and an indoline compound based on the related mass spectra. The FTIR spectra of the powder prepared from Solution A and the 1-amino-2-naphthol powder are quite similar and some characteristic peaks are observed in both of these spectra. On the other hand, the peak at $1737 \mathrm{~cm}^{-1}$ is only observed in the spectrum of the powder prepared from Solution A. This peak was assigned to the $\mathrm{C}=\mathrm{O}$ stretching vibration of the 
carboxyl group. Therefore, it is presumed that the indoline compound contained a carboxyl group.

The reaction process of SNO with acid is shown in Scheme 3. SNO is protonated in an acidic solution, forms $\mathrm{MCH}^{+}$, and then is transformed into $\mathrm{MC}-\mathrm{H}_{3} \mathrm{O}^{+}$by associating with a water molecule. In the present systems, a number of water molecules existed around these species. The water molecules were omitted in the molecular forms in the scheme. However, an important water molecule to determine the molecular form was shown in the $\mathrm{MC}-\mathrm{H}_{3} \mathrm{O}^{+}$form. In a highly acidic solution, the proton catalyzes the isomerization of $\mathrm{MC}-\mathrm{H}_{3} \mathrm{O}^{+}$followed by a water molecule addition to the $\mathrm{C}=\mathrm{N}$ bond, which is cleaved to produce 1-amino-2-naphtholate and 1,3,3-trimethylindoline carboxylic acid. This process is similar to the well-known hydrolysis of imines. The negative charge on each atom in $\mathrm{MC}$ and $\mathrm{MCH}^{+}$was calculated by the molecular orbital method. Their ground state structures were optimized at the DFT level using the B3LYP functional and the 6-31G basis set. The Mulliken charge on the oxygen atom of MC was estimated to be -0.494 and it was reasonably protonated. The charge on the nitrogen atom bonding to the naphthalene ring of $\mathrm{MCH}^{+}$was estimated to be -0.442 . This nitrogen atom can act as a Schiff base and hydrogen-bond to water molecule. The compounds, 1-amino-2-naphtholate and 1,3,3-trimethylindoline carboxylic acid, were reasonably produced in this study. This 
reaction having the constant $k_{4}$ was clearly promoted by $350-\mathrm{nm}$ light irradiation as shown in Table 1. This process can be thermally induced after the internal conversion because the absorption band at around $350 \mathrm{~nm}$ is not due to its main $\pi$-conjugated skeleton, which exhibits the 450-nm absorption.

(Scheme 3)

\section{Conclusions}

The reactions of SNO in an ethanol solution containing hydrochloric acid were observed in the dark and during UV irradiation by spectroscopic measurements in order to reveal the interaction between $\mathrm{SNO}$ and protons. $\mathrm{SNO}$ was protonated to form $\mathrm{MCH}^{+}$and then transformed into a complex in the acidic ethanol solution in the dark. It is presumed that the complex contains a hydrated proton and its structure is similar to that of the metal complex of $\mathrm{MC}, \mathrm{MC}-\mathrm{H}_{3} \mathrm{O}^{+}$, based on its UV-vis absorption and fluorescence spectra. The fluorescence quantum yield of $\mathrm{MC}-\mathrm{H}_{3} \mathrm{O}^{+}$was lower than that of $\mathrm{MC}^{-\mathrm{Al}^{3+}}$ because the fluorescence process of such complexes depends on the electron affinity of the metal ion, which occupies the unshared electron pair on the imine $\mathrm{N}$ which quenches the fluorescence. The complex dissociated and reproduced SNO by adding base. The complex was further changed under the acidic conditions after a long time. Highly concentrated acid induced 
the decomposition of SNO to the indoline compound with a carboxyl group and 1-amino-2-naphthol, which was revealed by fluorescence, IR, and GC-MS analyses. The first protonation process was photochemically promoted, while the others were thermally promoted by UV irradiation.

\section{References}

[1] H. Dürr, Photochromism: Molecules and Systems, Elsevier, Amsterdum, 2003, pp. 1-14.

[2] M. Irie, Chem. Rev. 100 (2000) 1683-1684.

[3] G. Berkovic, V. Krongauz, V. Welss, Chem. Rev. 100 (2000) 1741-1753.

[4] S. Kawata, Y. Kawata, Chem. Rev. 100 (2000) 1777-1788.

[5] K. Matsuda, M. Irie, J. Photochem. Photobiol. C 5 (2004) 169-182.

[6] W. Yuan, L. Sun, H. Tang, Y. Wen, G. Jiang, W. Huang, L. Jiang, Y. Song, H. Tian, D. Zhu, Adv. Mater. 17 (2005) 156-160.

[7] J. Zhou, F. Zhou, Y. Li, F. Zhang, X. Song, J. Photochem. Photobiol. A 92 (1995) 193-199.

[8] M. J. Preigh, F. Lin, K. Z. Ismail, S. G. Weber, J. Chem. Soc., Chem. Commun. (1995) 2091-2092. 
[9] K. Kimura, Coord. Chem. Rev. 148 (1996) 41-61.

[10] H. Görner, A. K. Chibisov, J. Chem. Soc., Faraday Trans. 94 (1998) 2557-2564.

[11] V. V. Korolev, D. Y. Vorobyev E. M. Glebov, V. P. Grivin, V. F. Plyusnin, A. V. Koshkin, O. A. Fedorova, S. P. Gromov, M. V. Alfimov, Y. V. Shklyaev, T. S. Vshivkova, Y. S. Rozhkova, A. G. Tolstikov, V. V. Lokshin, A. Samat, J. Photochem. Photobiol. A: Chem. $192(2007) 75-83$.

[12] S. Kumar, D. Hernandez, B. Hoa, Y. Lee, J. S. Yang, A. McCurdy, Org. Lett. 10 (2008) 3761-3764.

[13] M. Natali, L. Soldi, S. Giordani, Tetrahedron 66 (2010) 7612-7617.

[14] H. Nishikiori, N. Tanaka, K. Takagi, T. Fujii, Res. Chem. Intermed. 29 (2003) 485-493.

[15] H. Nishikiori, R. Sasai, K. Takagi, T. Fujii, Langmuir 22 (2006) 3376-3380.

[16] H. Nishikiori, N. Tanaka, K. Takagi, T. Fujii, J. Photochem. Photobiol. A 183 (2006) $53-58$.

[17] H. Nishikiori, N. Tanaka, K. Takagi, T. Fujii, J. Photochem. Photobiol. A 189 (2007) $46-54$.

[18] H. Nishikiori, K. Teshima, T. Fujii, Photochem Photobiol. Sci. 11 (2012) 1164-1173.

[19] V. I. Minkin, Chem. Rev. 104 (2004) 2751-2776.

[20] P. J. Castro, I. Gómez, M. Cossi, M. Reguero, J. Phys. Chem. A 116 (2012) 8148-8158. 
[21] S. H. Kim, S. Wang, C. H. Ahn, M. S. Choi, Fibers Polymers 8 (2007) 447-449.

[22] Z. Tian, R. A. Stairs, M. Wyer, N. Mosey, J. M. Dust, T. M. Kraft, E. Buncel, J. Phys. Chem. A 114 (2010) 11900-11909.

[23] N. Y. C. Chu, in: H. Dürr, H. Bouas-Laurent (Eds.), Photochromism: Molecules and Systems, Elsevier, Amsterdum, 2003, pp. 506-507.

[24] H. Nishikiori, T. Takamura, S. Shimamura, T. Fujii, J. Photochem. Photobiol. A 222 (2011) 236-240.

[25] J. Biteau, F. Chaput, J. -P. Boilot, J. Phys. Chem. 100 (1996) 9024-9031.

[26] X. Sun, M. Fan, E. T. Knobbe, Mol. Cryst. Liq. Cryst. 297 (1997) 57-64.

[27] A. Lafuma, S. Chodorowski-Kimmes, F. X. Quinn, C. Sanchez, Eur. J. Inorg. Chem. (2003) 331-338.

[28] T. Fujii, T. Mabuchi, H. Kitamura, O. Kawauchi, N. Negishi, M. Anpo, Bull. Chem. Soc. Jpn. 65 (1992) 720-727.

[29] N. Y. C. Chu, Can. J. Chem. 61 (1983) 300-305.

[30] G. Favaro, F. Masetti, U. Mazzucato, G. Ottavi, P. Allegrini, V. Malatesta, J. Chem. Soc. Faraday Trans. 90 (1994) 333-338.

[31] N. W. Tyer, Jr., R. S. Becker, J. Am. Chem. Soc. 92 (1970) 1289-1294.

[32] P. Rys, R. Weber, Q. Wu, Can. J. Chem. 71 (1993) 1828-1833. 
[33] X. D. Sun, M. G. Fan, X. J. Meng, E. T. Knobbe, J. Photochem. Photobiol. A 102 (1997) 213-216.

[34] H. Grasdalen, J. Magn. Reson. 5 (1971) 84-93.

[35] A. Samadi-Maybodi, Spectrochim. Acta A 64 (2006) 1025-1031.

[36] S. Schneider, Z. Phys. Chem. Neue Folge 154 (1987) 91-119.

[37] A. Kellmann, F. Tfibel, R. Dubest, P. Levoir, J. Aubard, E. Pottier, R. Guglielmetti, J. Photochem. Photobiol. A 49 (1989) 63-73.

[38] G. Favaro, V. Malatesta, U. Mazzucato, G. Ottavi, A. Romani, J. Photochem. Photobiol. A 87 (1995) 235-241.

[39] M. Lawrence, C. J. Marzzacco, C. Morton, C. Schwab, A. M. Halpern, J. Phys. Chem. 95 (1991) 10294-10299.

[40] A. A. El-Rayyes, H. P. Perzanowski, S. A. I. Barri, U. K. A. Klein J. Phys. Chem. A 105 (2001) 10169-10175. 
Table 1. Rate constant of each reaction process in acidic SNO ethanol solution, in which the molar ratio of $\mathrm{SNO}$ to $\mathrm{H}^{+}$was $3 / 100$.

\begin{tabular}{lllll}
\hline Condition & $k_{1} / \mathrm{s}^{-1}$ & $k_{2} / \mathrm{s}^{-1}$ & $k_{3} / \mathrm{s}^{-1}$ & $k_{4} / \mathrm{s}^{-1}$ \\
\hline Dark & $4.48 \times 10^{-4}$ & $2.89 \times 10^{-6}$ & $1.98 \times 10^{-7}$ & $2.73 \times 10^{-4}$ \\
UV irradiation & $9.57 \times 10^{-4}$ & $1.70 \times 10^{-5}$ & $5.69 \times 10^{-7}$ & $7.16 \times 10^{-4}$ \\
\hline
\end{tabular}




\section{Scheme titles and figure captions}

Scheme 1 Isomerization and metal chelation of SNO.

Scheme 2 Fluorescence processes of SNO isomers in solvents. The bold arrows indicate preferential processes.

Scheme 3 Reaction process of SNO with acid.

Figure 1 Change in UV-vis absorption spectrum of the $\mathrm{SNO}$ ethanol solution with $\mathrm{Al}^{3+}$ during UV irradiation, in which the molar ratio of $\mathrm{SNO}$ to $\mathrm{Al}^{3+}$ was 3/1.

Figure 2 Change in (a) fluorescence and (b) excitation spectra of the SNO ethanol solution with $\mathrm{Al}^{3+}$ during UV irradiation, in which the molar ratio of $\mathrm{SNO}$ to $\mathrm{Al}^{3+}$ was $3 / 1$. The fluorescence spectra were observed upon excitation at $370 \mathrm{~nm}$. The excitation spectra were observed at 445 and $540 \mathrm{~nm}$. 
Figure 3 Change in UV-vis absorption spectrum of the SNO ethanol solution with hydrochloric acid (a) in the dark, and (b) during the UV irradiation, in which the molar ratio of $\mathrm{SNO}$ to $\mathrm{H}^{+}$was $3 / 100$.

Figure 4 Time course of the absorbance values for the peaks of $\mathrm{MCH}^{+}(530 \mathrm{~nm})$ and $\mathrm{MC}-\mathrm{H}_{3} \mathrm{O}^{+}(450 \mathrm{~nm})$ observed in the $\mathrm{SNO}$ ethanol solution with hydrochloric acid (a) in the dark, and (b) during the UV irradiation, in which the molar ratio of $\mathrm{SNO}$ to $\mathrm{H}^{+}$was $3 / 100$.

Figure 5 Change in (a) fluorescence, and (b) excitation spectra of the SNO ethanol solution with hydrochloric acid during the UV irradiation, in which the molar ratio of $\mathrm{SNO}$ to $\mathrm{H}^{+}$was 3/100. The fluorescence spectra were observed upon excitation at $370 \mathrm{~nm}$. The excitation spectra were observed at 445 and $540 \mathrm{~nm}$.

Figure 6 Fluorescence intensity values at $540 \mathrm{~nm}$ for the solutions containing SNO and $\mathrm{Al}^{3+}\left(\mathrm{SNO} / \mathrm{Al}^{3+}=3 / 1\right)$ and $\mathrm{SNO}$ and $\mathrm{H}^{+}\left(\mathrm{SNO} / \mathrm{H}^{+}=3 / 100\right)$ plotted versus the related absorbance values. 
Figure 7 Fluorescence and excitation spectra of (a) the acidic SNO ethanol solution allowed to react for $24 \mathrm{~h}$ during UV irradiation compared to those of (b) 1-amino-2-naphthol. The fluorescence spectra were observed upon excitation at (1) 287 , and (2) $370 \mathrm{~nm}$. The excitation spectra were observed at (3) 365, and (4) $445 \mathrm{~nm}$. 


\section{Scheme titles and figure captions}

Scheme 1 Isomerization and metal chelation of SNO.

Scheme 2 Fluorescence processes of SNO isomers in solvents. The bold arrows indicate preferential processes.

Scheme 3 Reaction process of SNO with acid.

Figure 1 Change in UV-vis absorption spectrum of the $\mathrm{SNO}$ ethanol solution with $\mathrm{Al}^{3+}$ during UV irradiation, in which the molar ratio of $\mathrm{SNO}$ to $\mathrm{Al}^{3+}$ was 3/1.

Figure 2 Change in (a) fluorescence and (b) excitation spectra of the SNO ethanol solution with $\mathrm{Al}^{3+}$ during UV irradiation, in which the molar ratio of $\mathrm{SNO}$ to $\mathrm{Al}^{3+}$ was $3 / 1$. The fluorescence spectra were observed upon excitation at $370 \mathrm{~nm}$. The excitation spectra were observed at 445 and $540 \mathrm{~nm}$. 
Figure 3 Change in UV-vis absorption spectrum of the SNO ethanol solution with hydrochloric acid (a) in the dark, and (b) during the UV irradiation, in which the molar ratio of $\mathrm{SNO}$ to $\mathrm{H}^{+}$was $3 / 100$.

Figure 4 Time course of the absorbance values for the peaks of $\mathrm{MCH}^{+}(530 \mathrm{~nm})$ and $\mathrm{MC}-\mathrm{H}_{3} \mathrm{O}^{+}(450 \mathrm{~nm})$ observed in the $\mathrm{SNO}$ ethanol solution with hydrochloric acid (a) in the dark, and (b) during the UV irradiation, in which the molar ratio of $\mathrm{SNO}$ to $\mathrm{H}^{+}$was $3 / 100$.

Figure 5 Change in (a) fluorescence, and (b) excitation spectra of the SNO ethanol solution with hydrochloric acid during the UV irradiation, in which the molar ratio of $\mathrm{SNO}$ to $\mathrm{H}^{+}$was 3/100. The fluorescence spectra were observed upon excitation at $370 \mathrm{~nm}$. The excitation spectra were observed at 445 and $540 \mathrm{~nm}$.

Figure 6 Fluorescence intensity values at $540 \mathrm{~nm}$ for the solutions containing SNO and $\mathrm{Al}^{3+}\left(\mathrm{SNO} / \mathrm{Al}^{3+}=3 / 1\right)$ and $\mathrm{SNO}$ and $\mathrm{H}^{+}\left(\mathrm{SNO} / \mathrm{H}^{+}=3 / 100\right)$ plotted versus the related absorbance values. 
Figure 7 Fluorescence and excitation spectra of (a) the acidic SNO ethanol solution allowed to react for $24 \mathrm{~h}$ during UV irradiation compared to those of (b) 1-amino-2-naphthol. The fluorescence spectra were observed upon excitation at (1) 287 , and (2) $370 \mathrm{~nm}$. The excitation spectra were observed at (3) 365, and (4) $445 \mathrm{~nm}$. 
Scheme 1
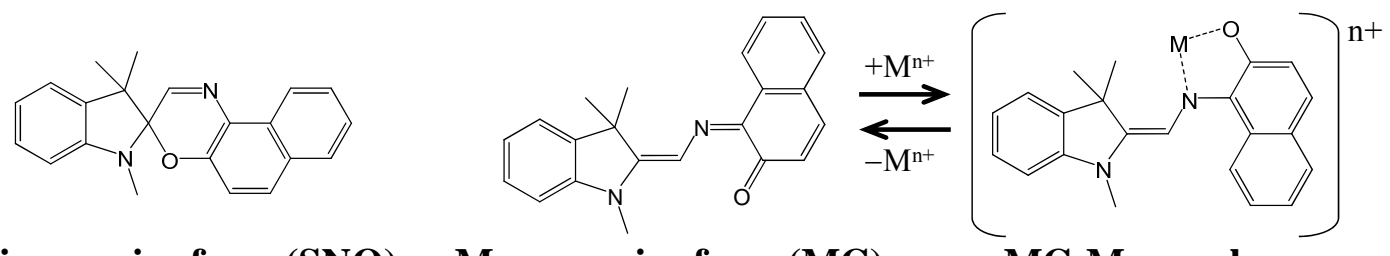

Spirooxazine form (SNO)

Merocyanine form (MC)<smiles>C1CCC2CCCC2C1</smiles>
colorless

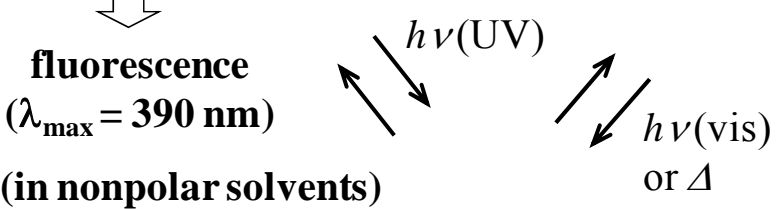

blue

MC-M complex yellow

$$
\begin{gathered}
\text { fluorescence } \\
\left(\lambda_{\max }=540 \mathrm{~nm}\right)
\end{gathered}
$$

(in nonpolar solvents)

or $\Delta$

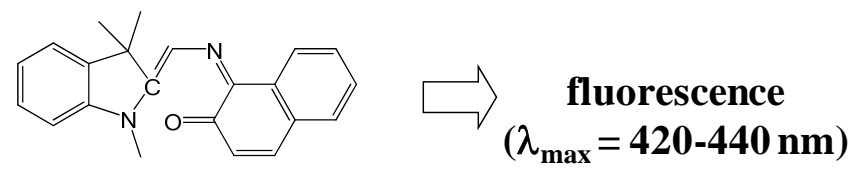

Intermediate species $\left(X_{s}\right.$ and $\left.X_{h}\right) \quad$ (in polar solvents) 
Scheme 2

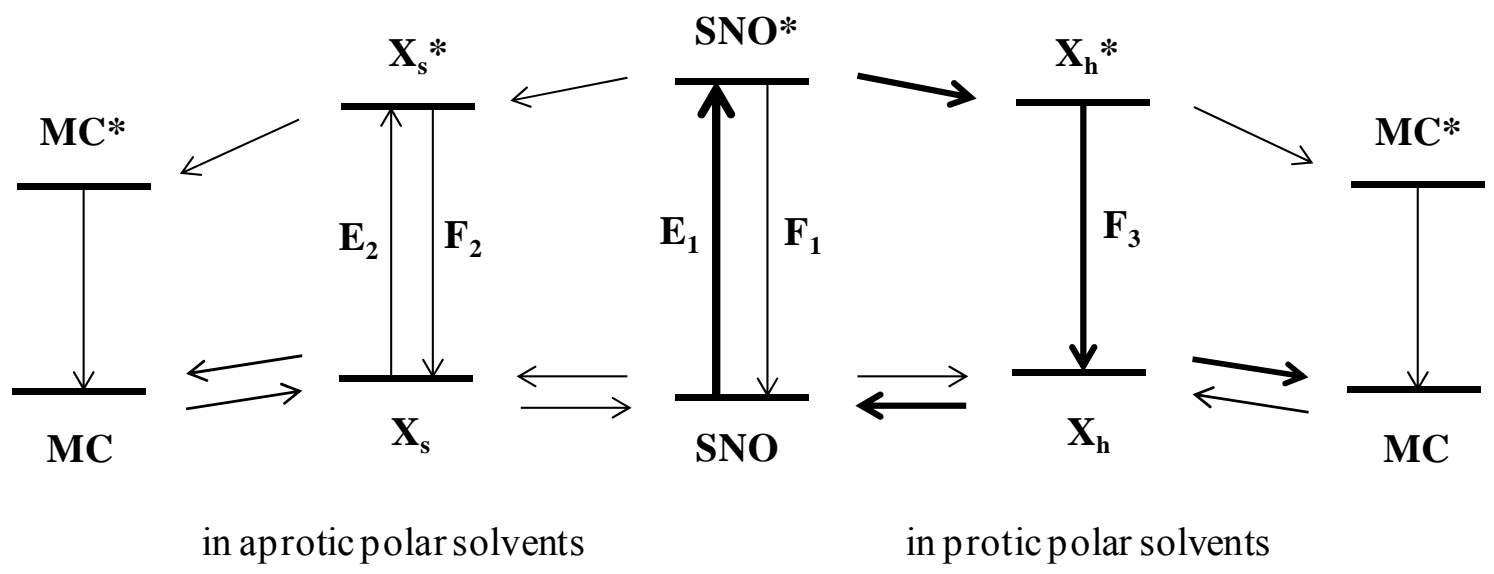




\section{Scheme 3}
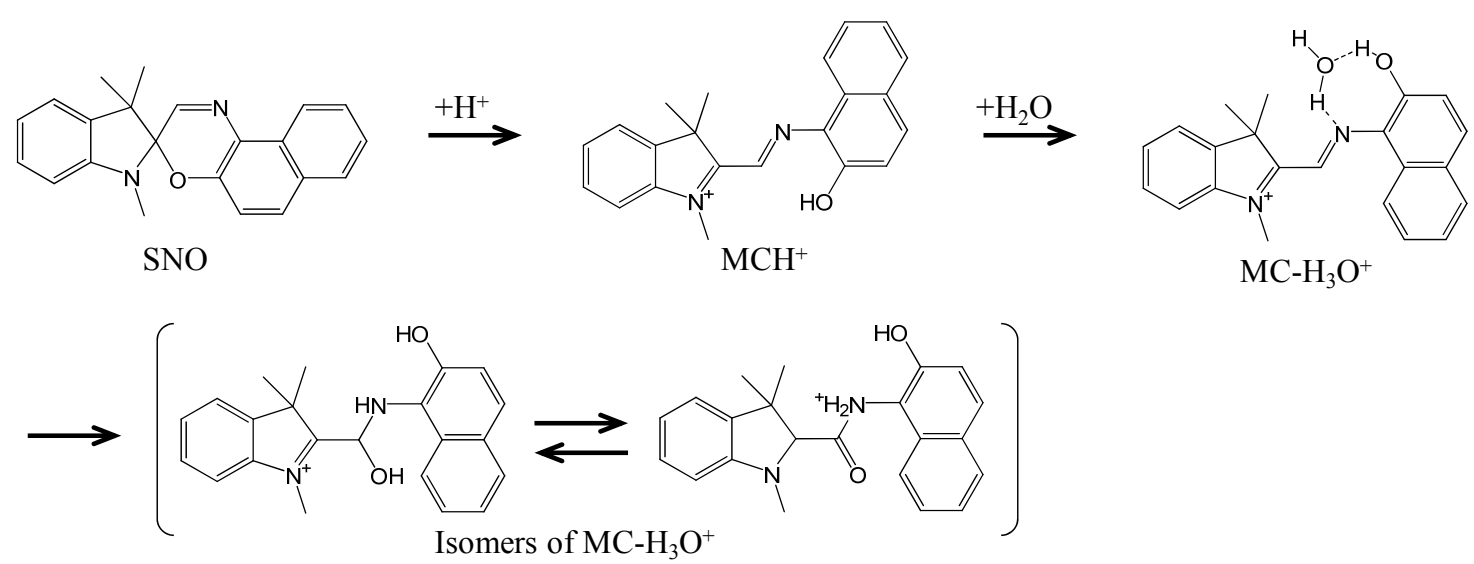

$\stackrel{+\mathrm{H}_{2} \mathrm{O}}{\longrightarrow}$ 
Figure 1

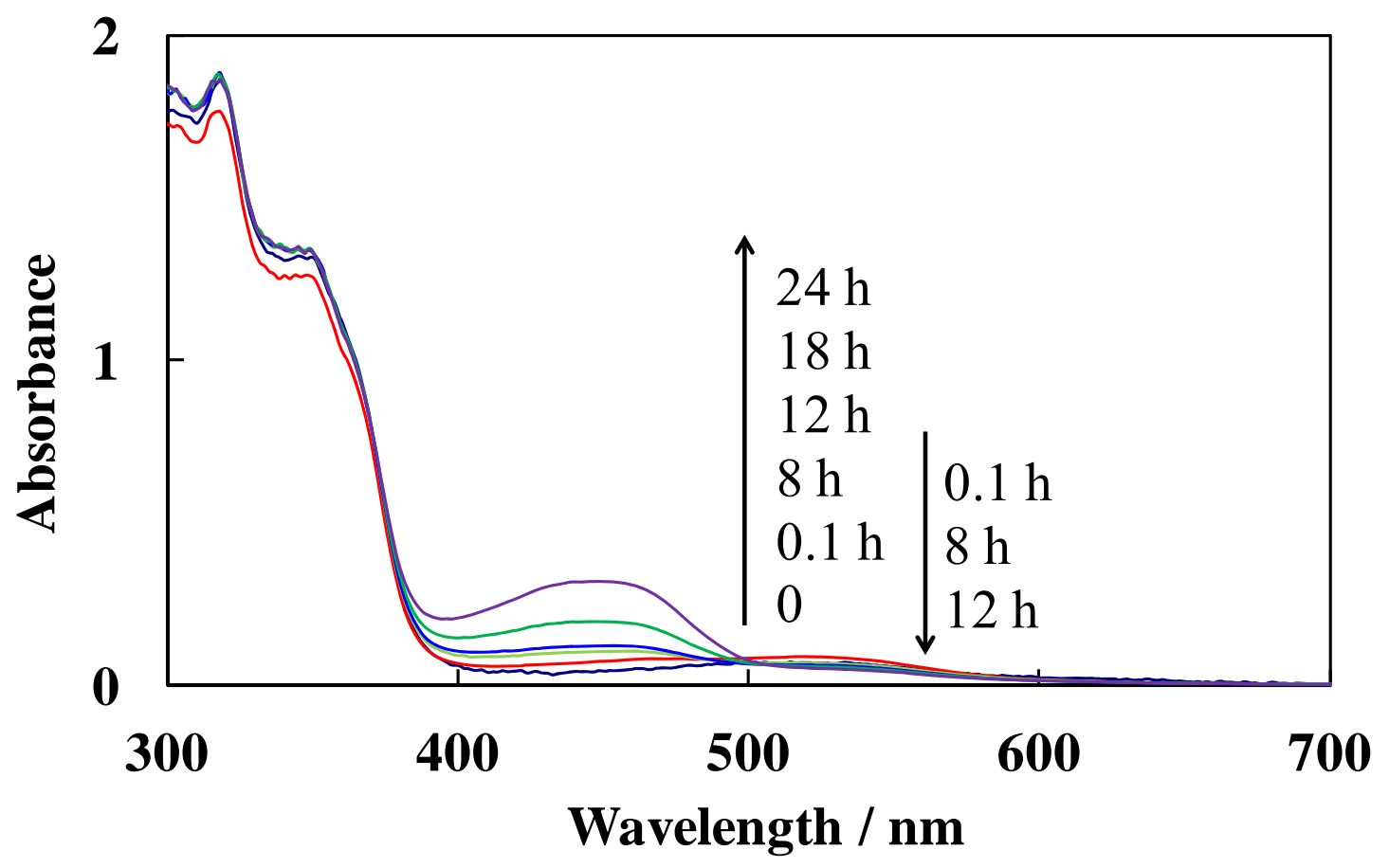


Figure 2

(a)

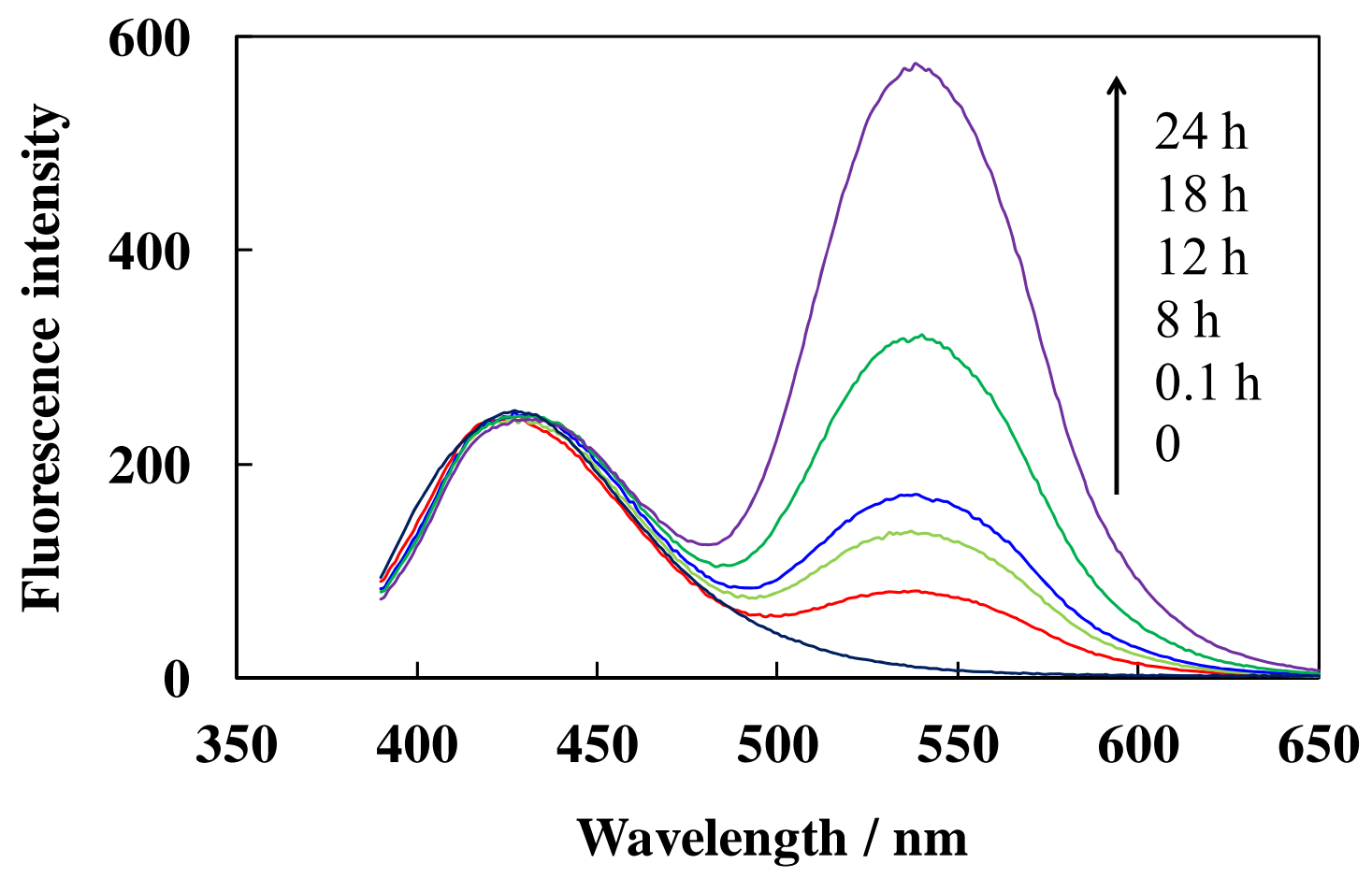

(b)

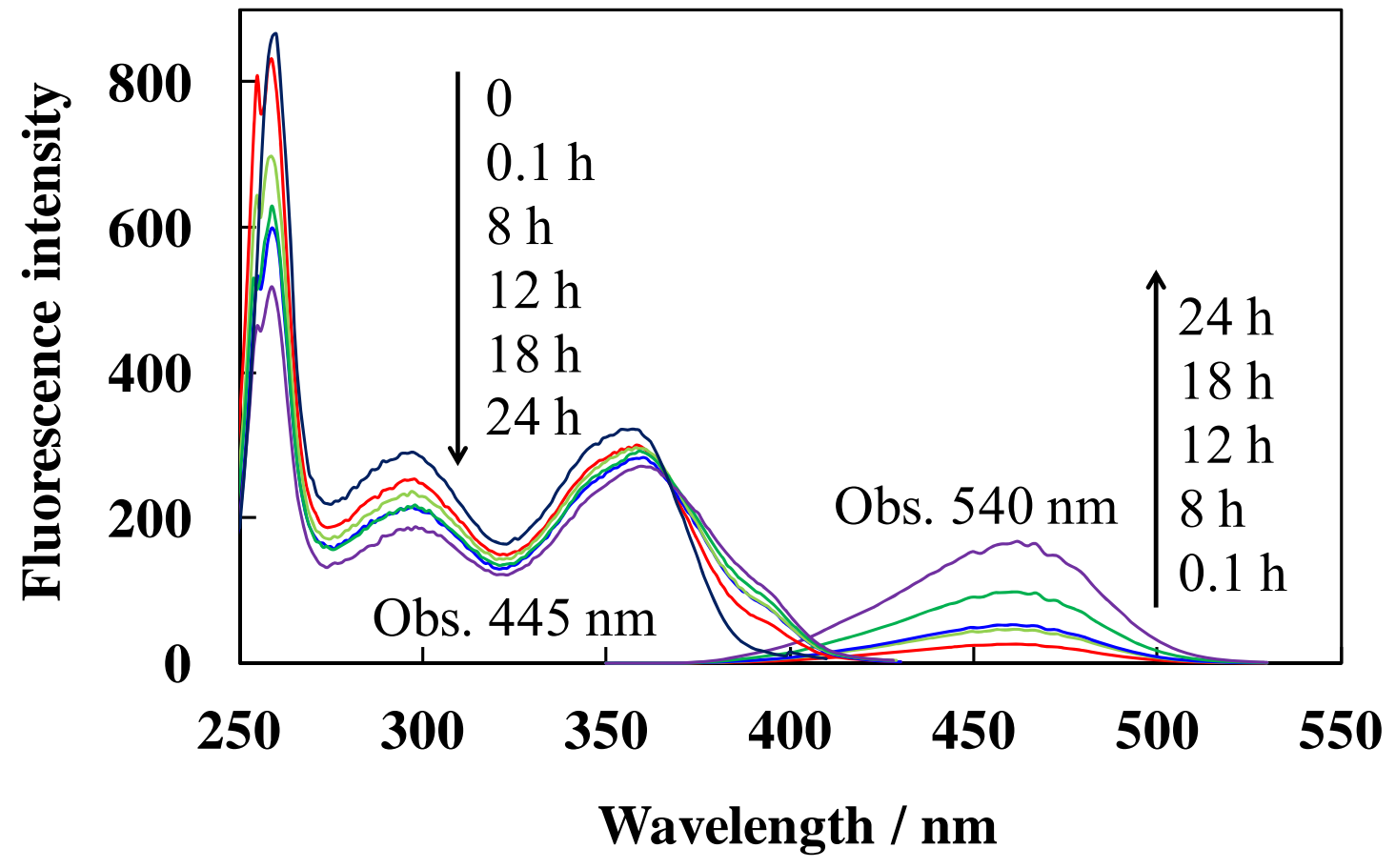


Figure 3

(a)

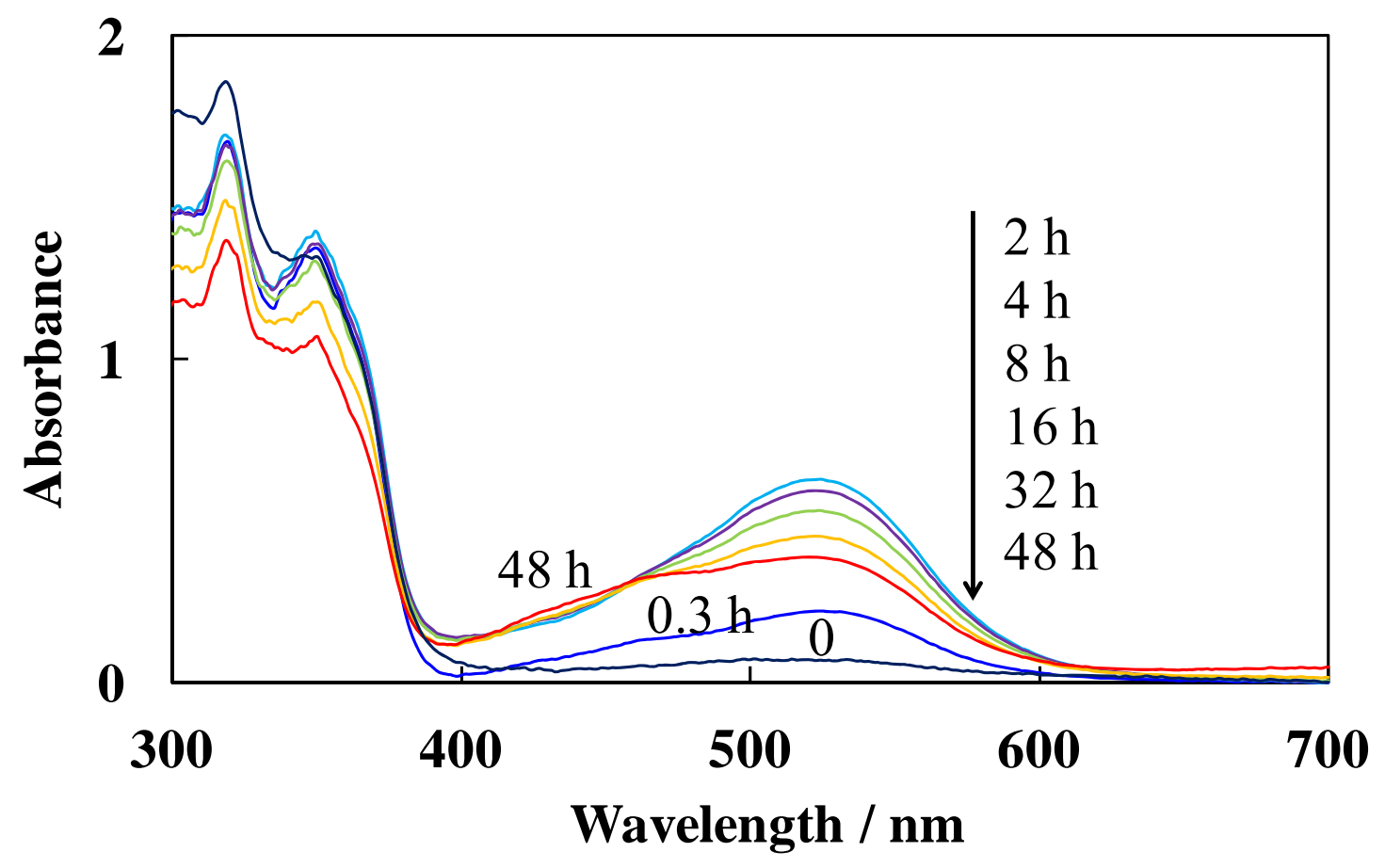

(b)

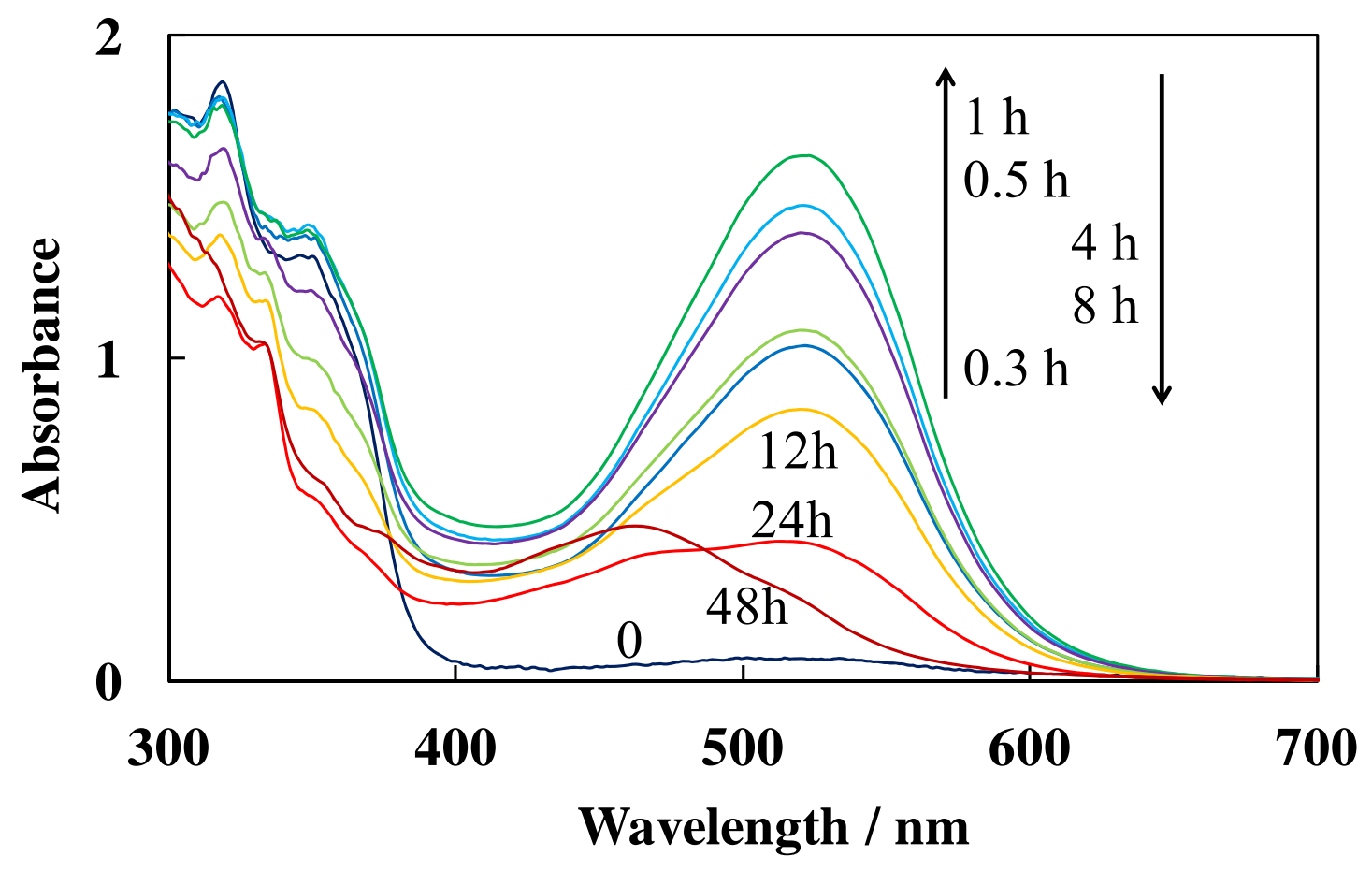


Figure 4

(a)

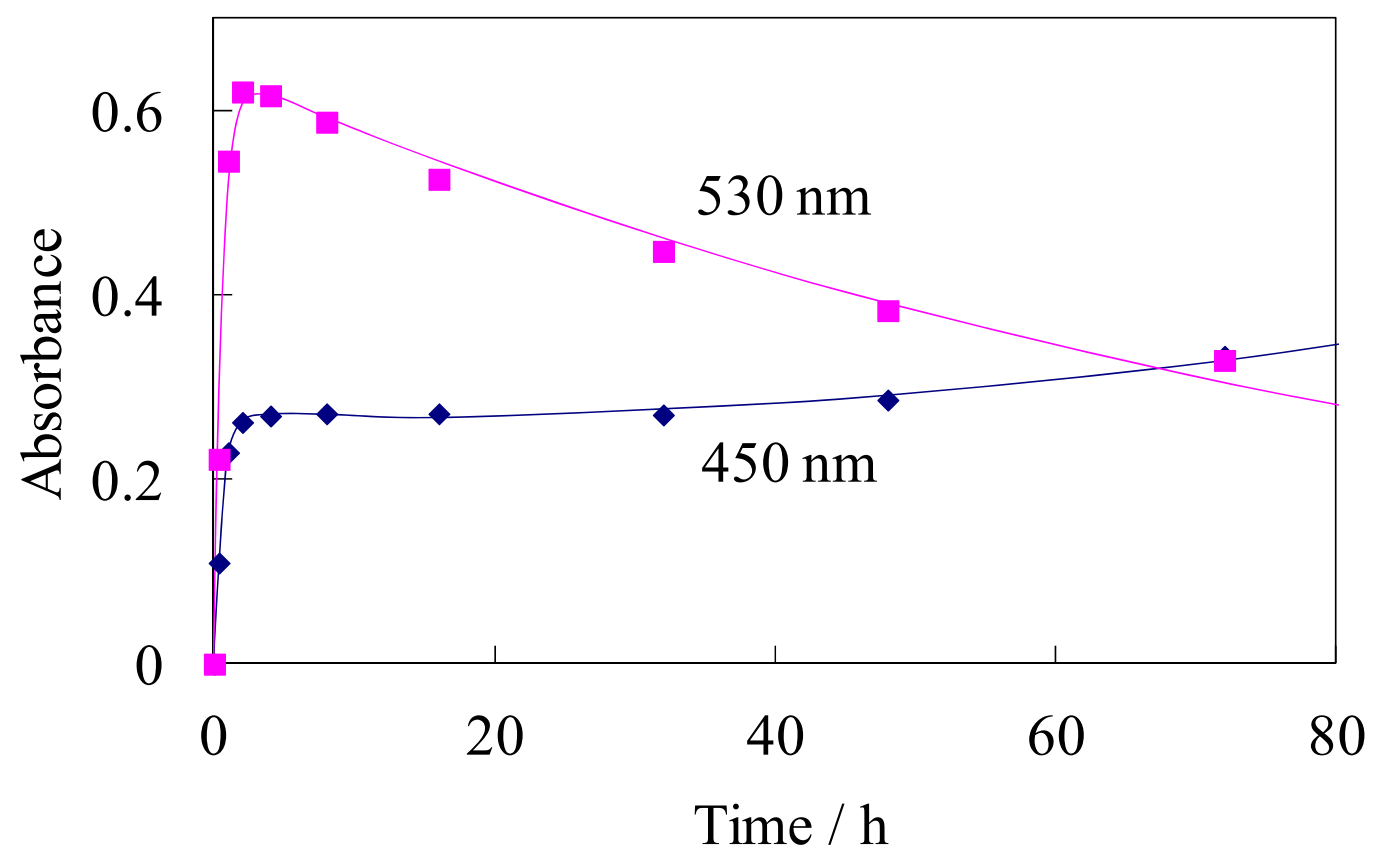

(b)

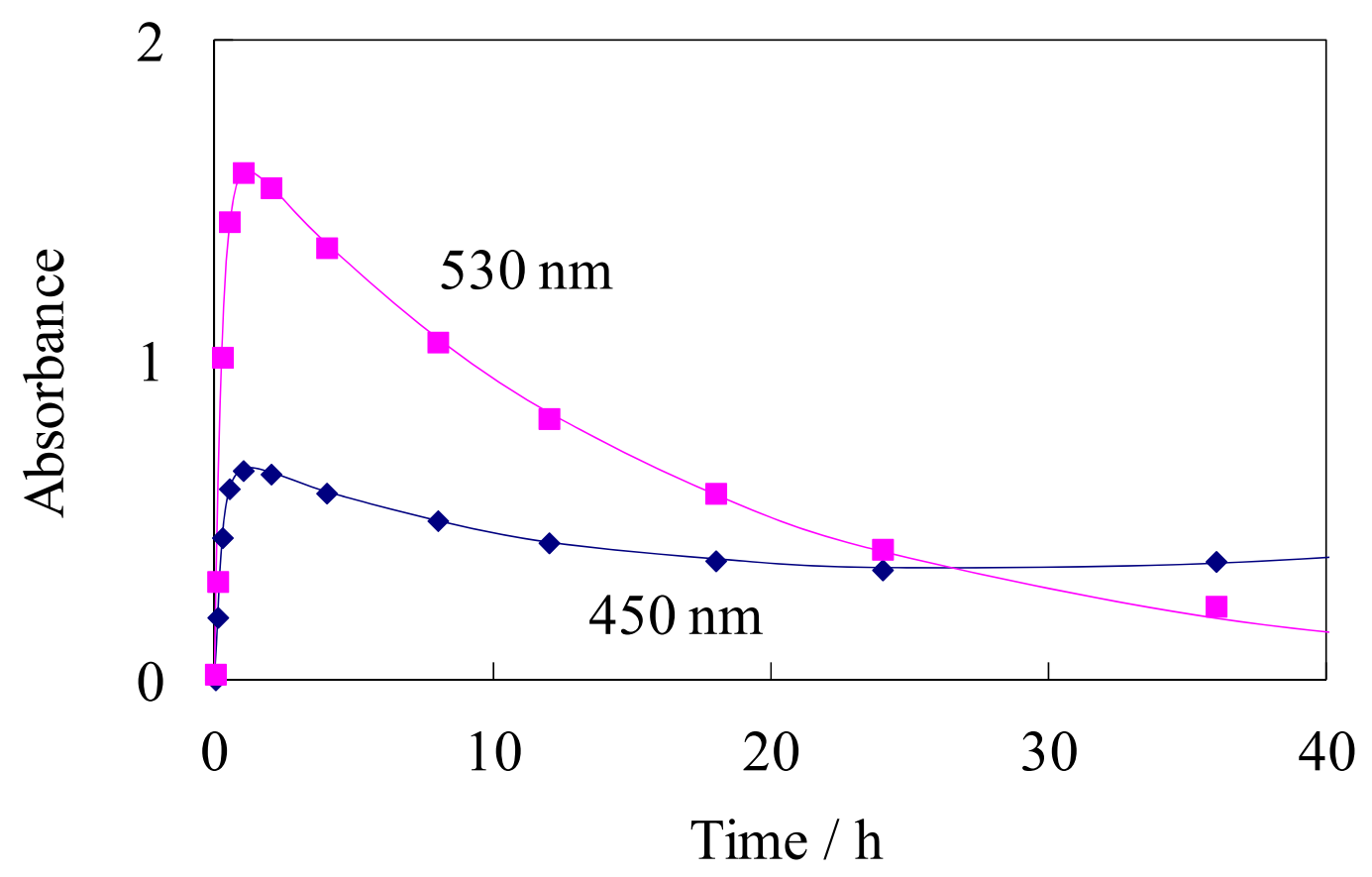


Figure 5

(a)

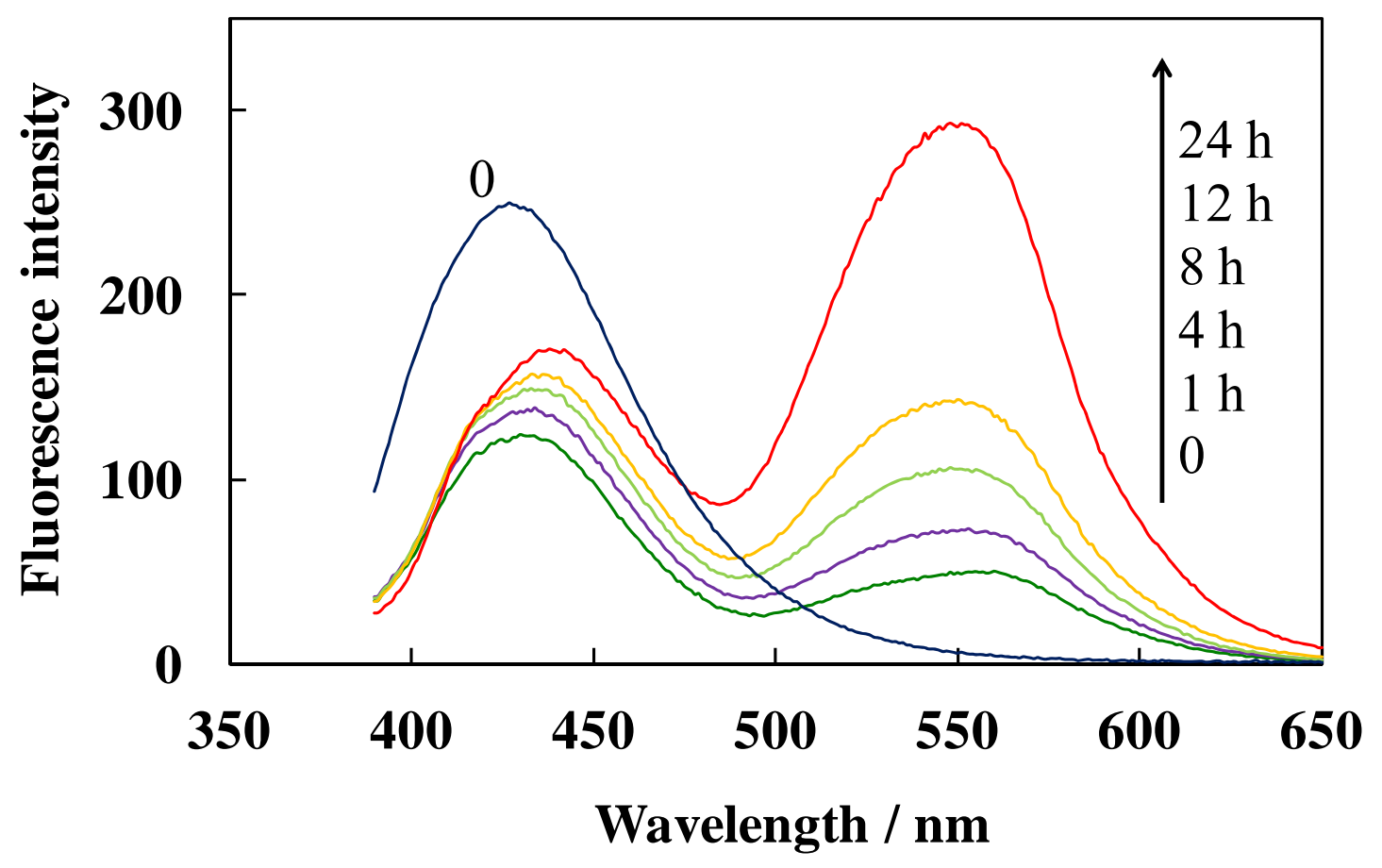

(b)

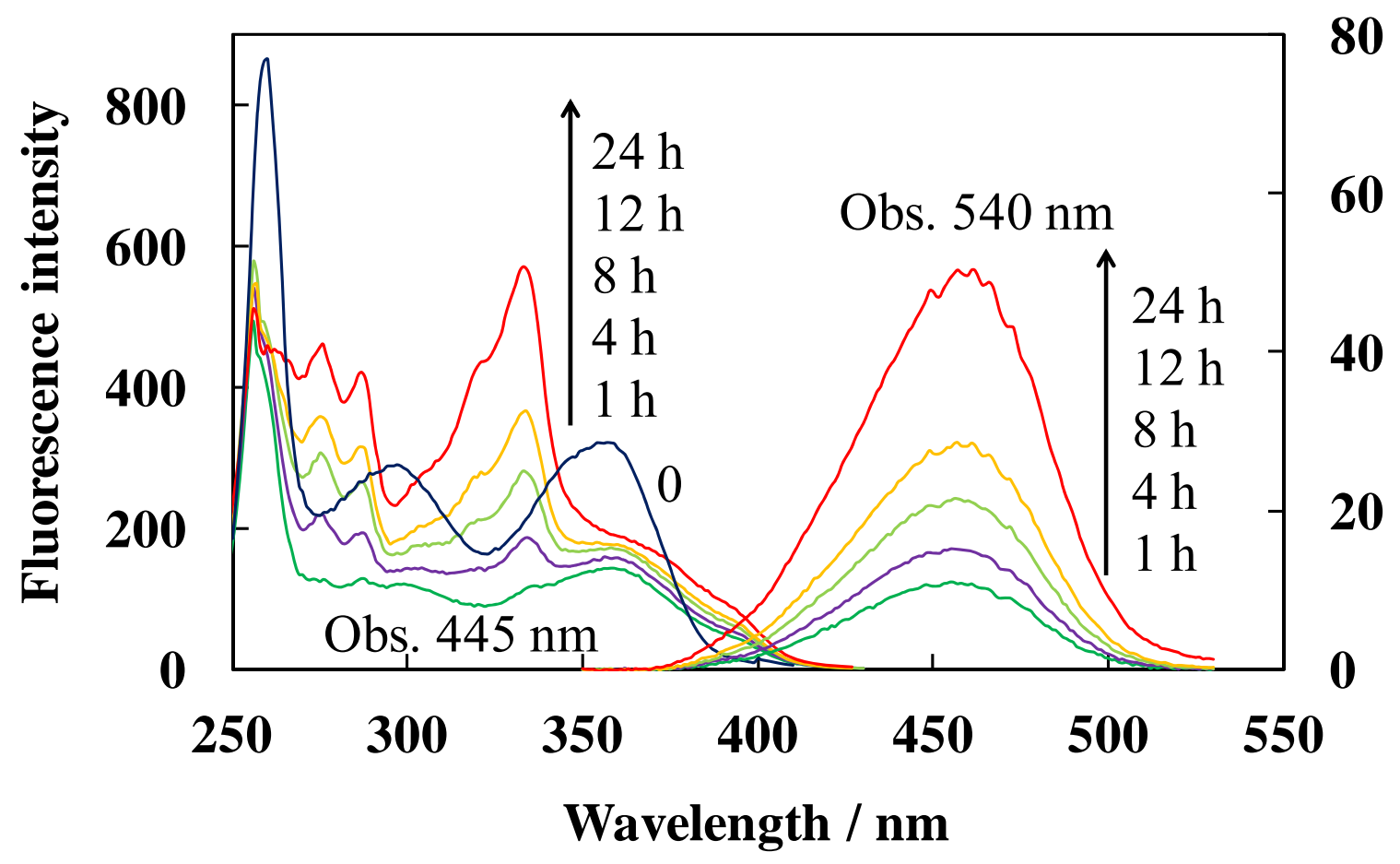


Figure 6

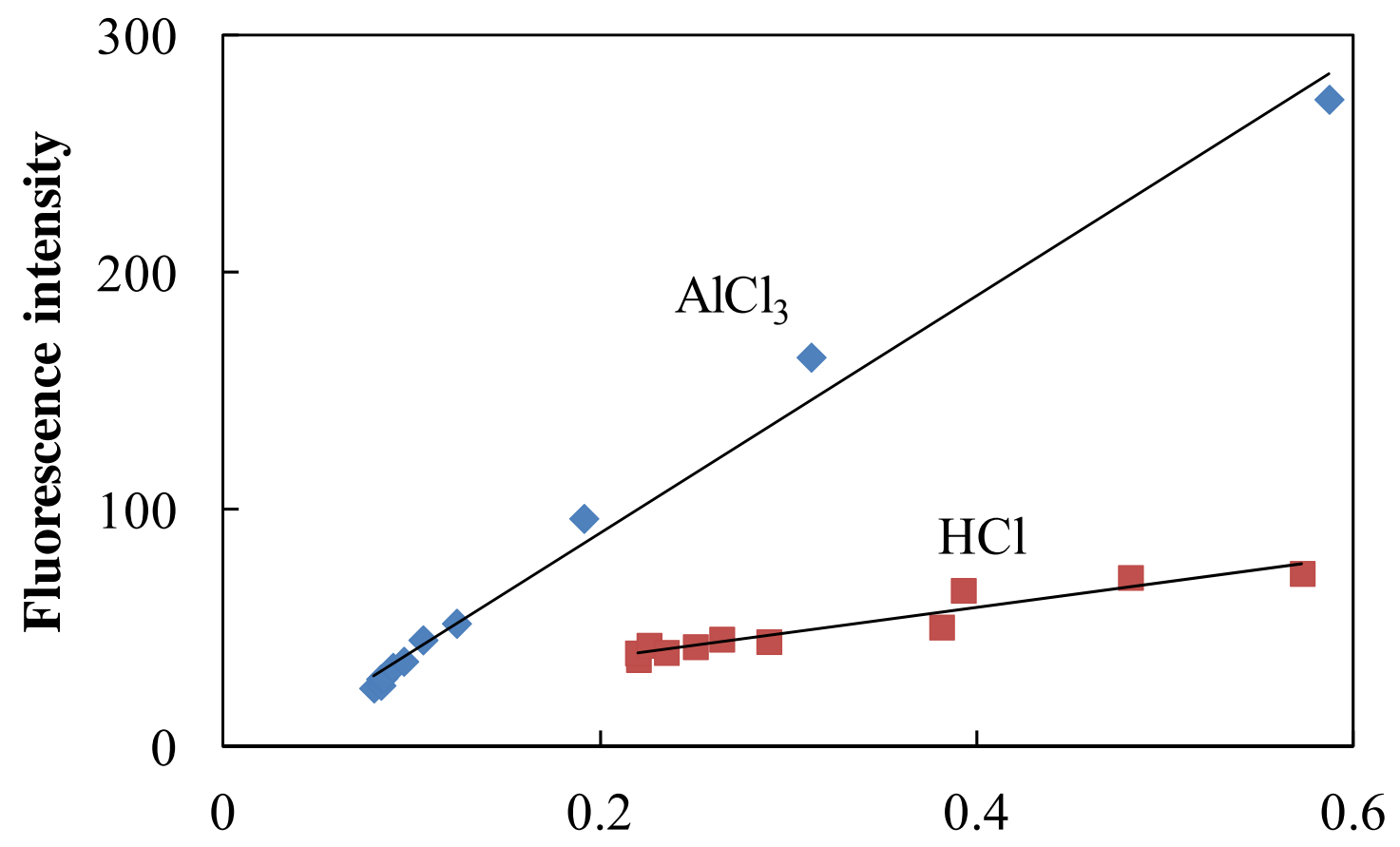

Absorbance 
Figure 7

(a)

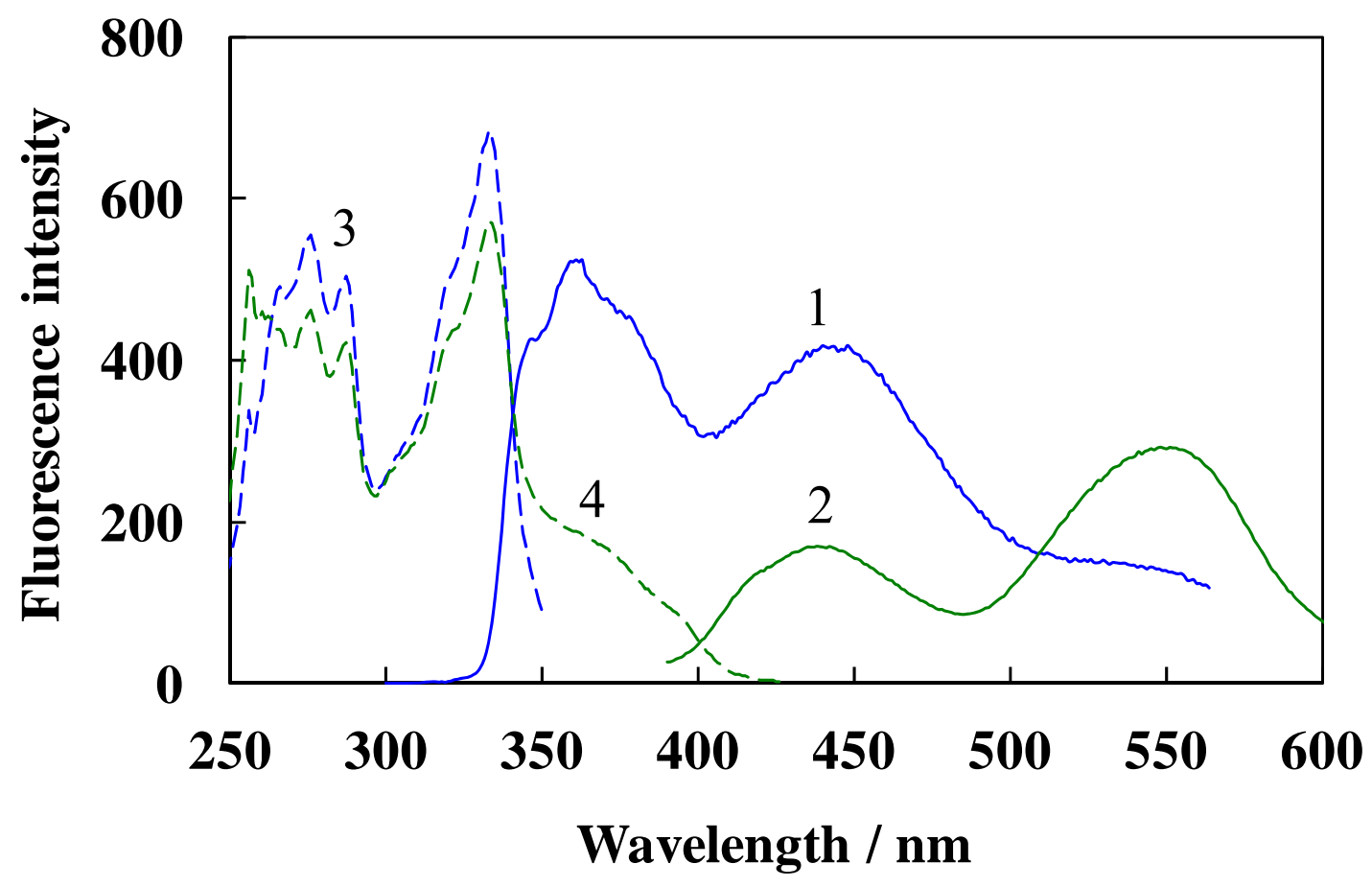

(b)

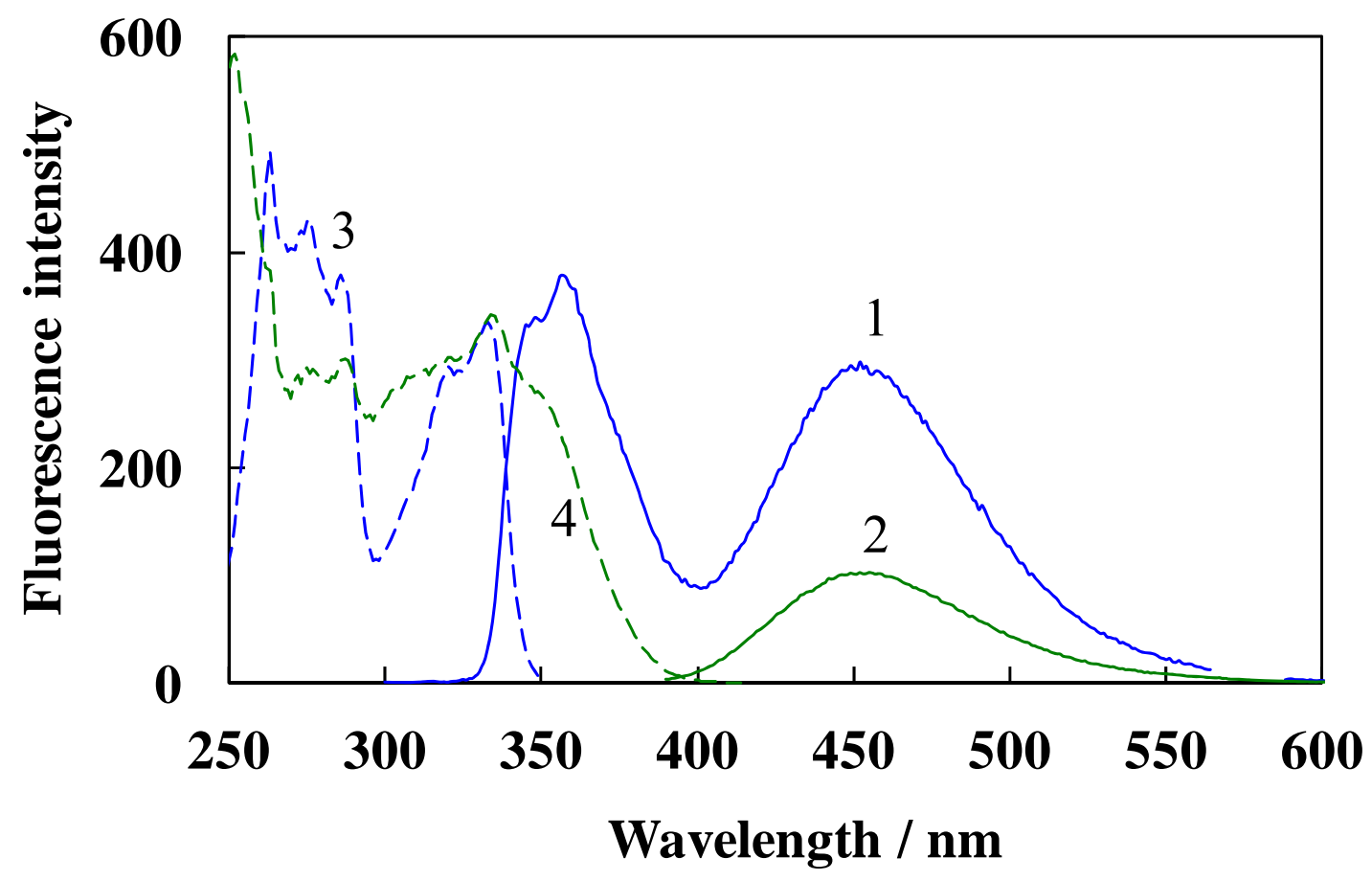




\section{Supplementary data}

Figure S1 (a) UV-vis absorption, (b) fluorescence, and (c) excitation spectra of the acidic SNO ethanol solution allowed to react for $48 \mathrm{~h}$ in the dark observed before and after adding the sodium hydroxide solution.

The absorption band at $400-600 \mathrm{~nm}$ due to $\mathrm{MCH}^{+}$and $\mathrm{MC}-\mathrm{H}_{3} \mathrm{O}^{+}$disappeared and the absorbance at 300-370 nm due to SNO increased by adding base. With this behavior, the fluorescence and excitation bands at around $540 \mathrm{~nm}$ and $460 \mathrm{~nm}$, respectively, assigned to MC- $\mathrm{H}_{3} \mathrm{O}^{+}$decreased and those at around 425 and $250-400 \mathrm{~nm}$, respectively, assigned to $\mathrm{X}_{\mathrm{h}}$ increased. The spectral red-shift compared to the original $\mathrm{X}_{\mathrm{h}}$ spectra is due to the solvent effect by adding an aqueous sodium hydroxide solution. The dissociation of $\mathrm{MC}-\mathrm{H}_{3} \mathrm{O}^{+}$was confirmed to occur by adding base. 


\section{Figure S1}

(a)

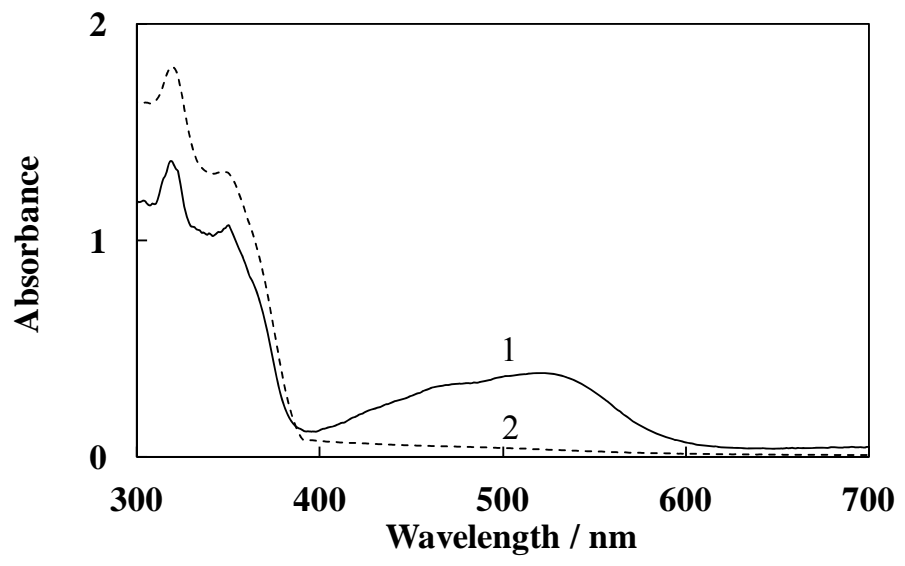

(b)

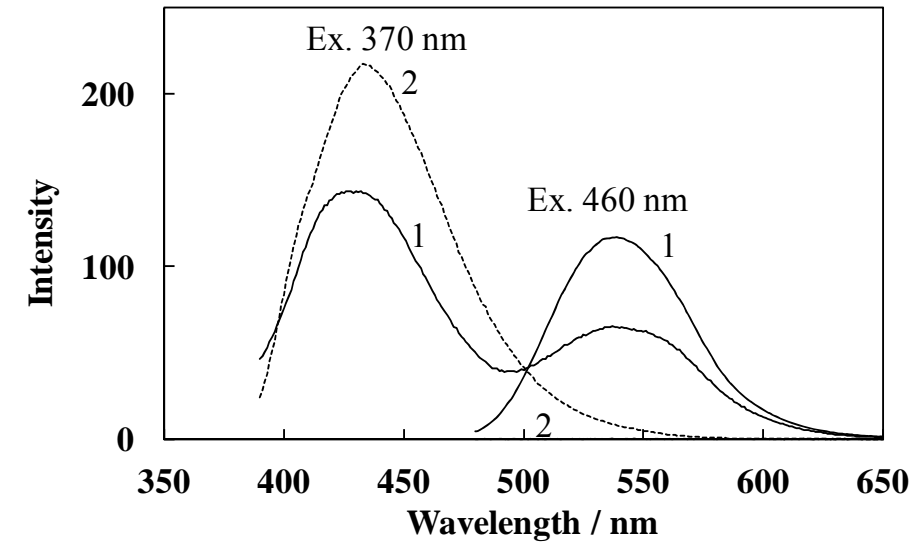

(c)

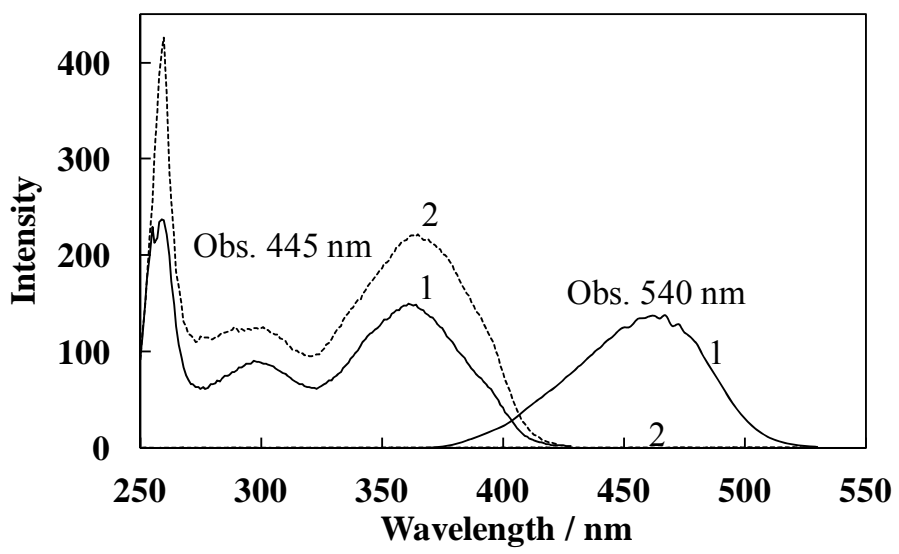


Figure S2 (a) Gas chromatogram and (b-d) mass spectra related to the retention time peaks at (b) 22.4 , (c) 23.7 , and (d) 23.9 min for Solution A.

The peaks are located at $22.4,23.7$, and $23.9 \mathrm{~min}$ in the chromatogram of Fig. S2a. The mass spectra related to these peaks are shown in Figs. S2b, S2c, and S2d, respectively. The chromatogram peak at $22.4 \mathrm{~min}$ is due to $\mathrm{SNO}$ or MC based on the related mass spectrum exhibiting its molecular ion peak at m/z 327.95 and the peaks for the aminonaphthol and indoline fragments at $\mathrm{m} / \mathrm{z} 162.05$ and 177.20 , respectively. The small peak at $23.7 \mathrm{~min}$ was assigned to 1-amino-2-naphthol from the related mass spectrum exhibiting its molecular ion peak at $\mathrm{m} / \mathrm{z} 160.30$ and the peaks for the aminonaphtalene or naphthol fragment at $\mathrm{m} / \mathrm{z} 144.45$. The largest peak at 23.9 min should be assigned to an indoline compound having a functional group from the related mass spectrum exhibiting a peak for the molecular ion of the indoline compound at $\mathrm{m} / \mathrm{z} 206.35$ and those for the demethylated fragments at $\mathrm{m} / \mathrm{z} 190.95,175.05$, and 160.15. On the other hand, 1,3,3-trimethyloxindole known as a photooxidized product was observed in the chromatogram peak at around $23.5 \mathrm{~min}$ for the solution allowed to react for a longer time during the UV irradiation. 
Figure S2

(a)

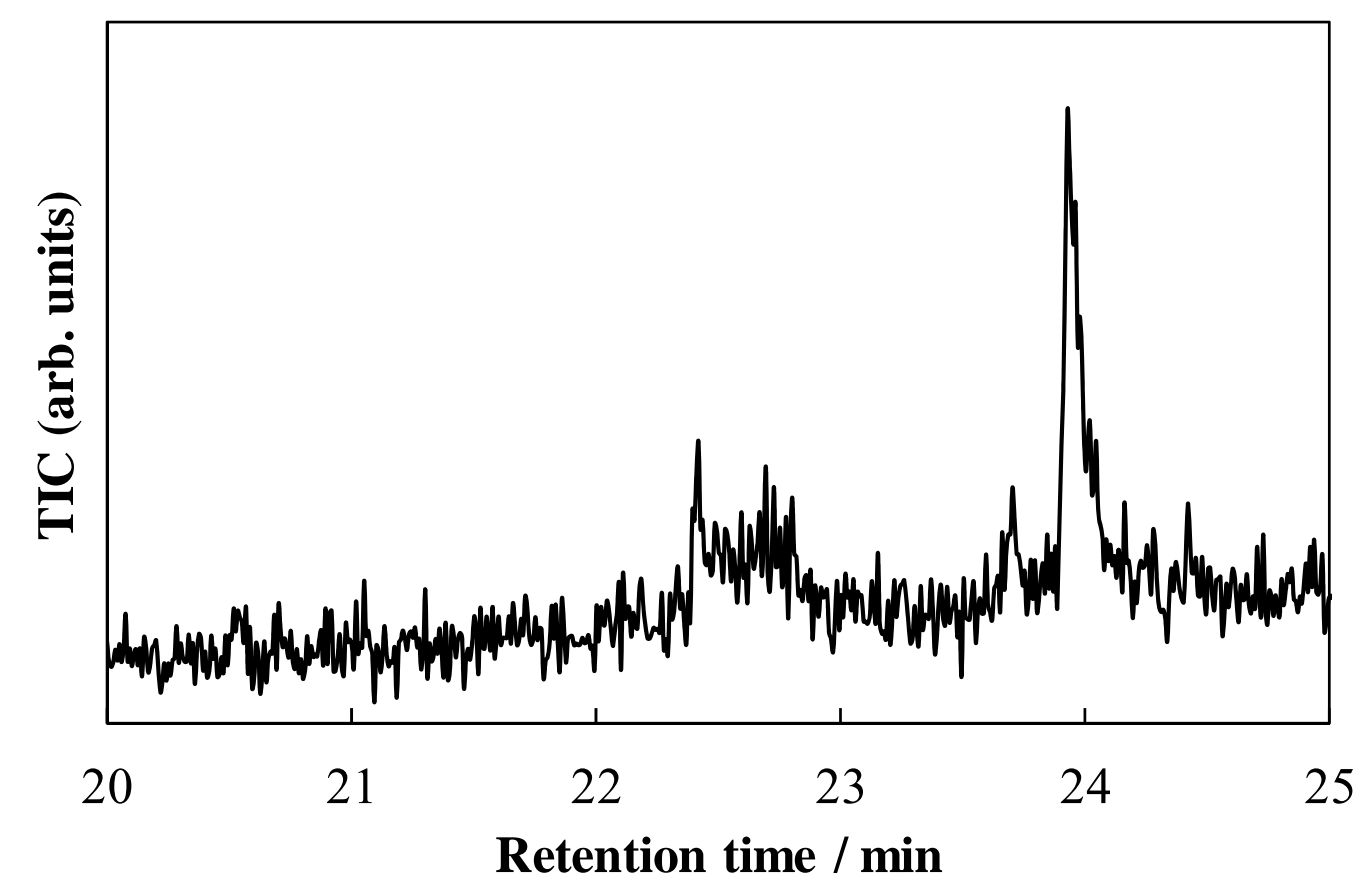

(b)

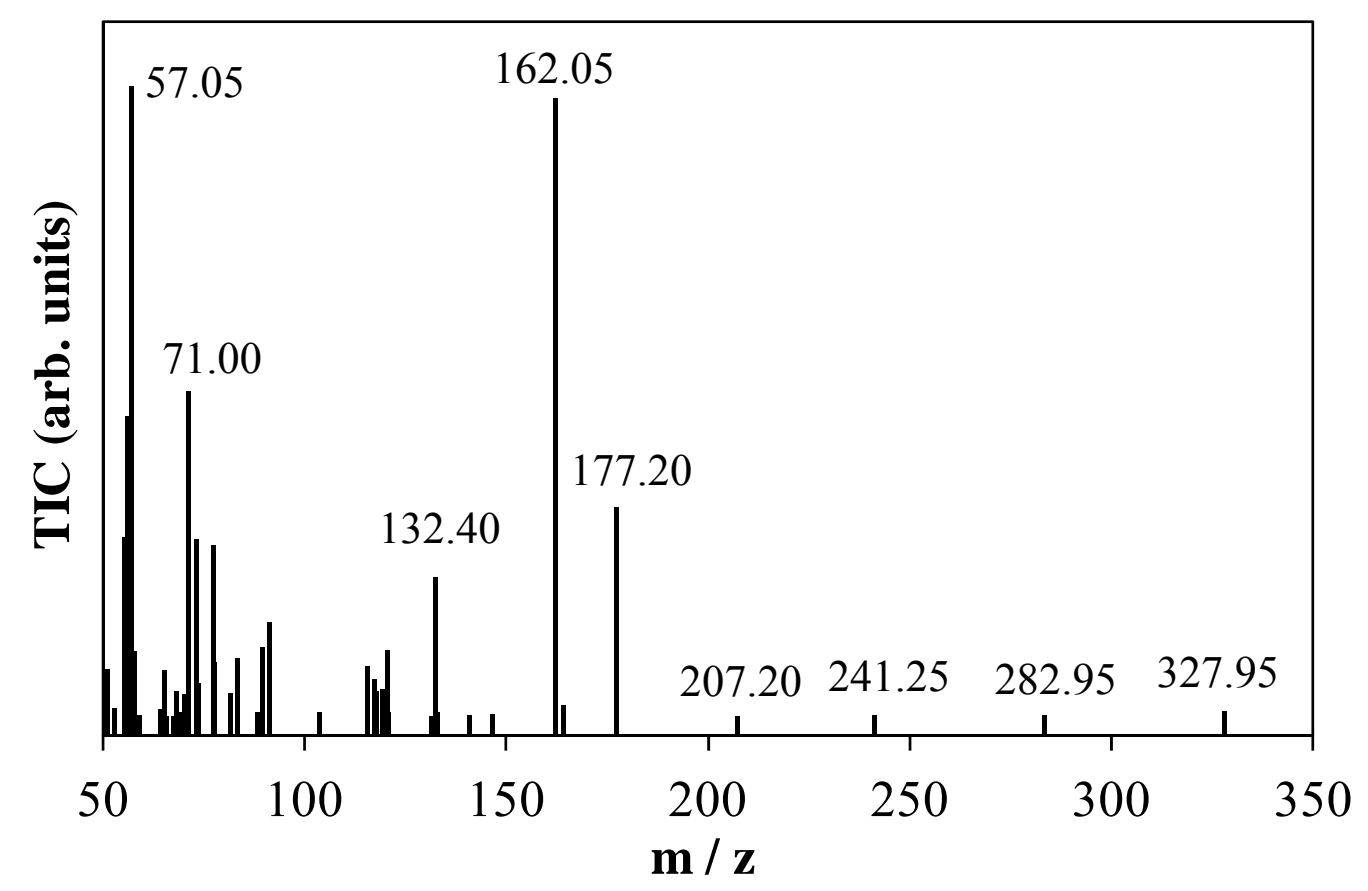


(c)

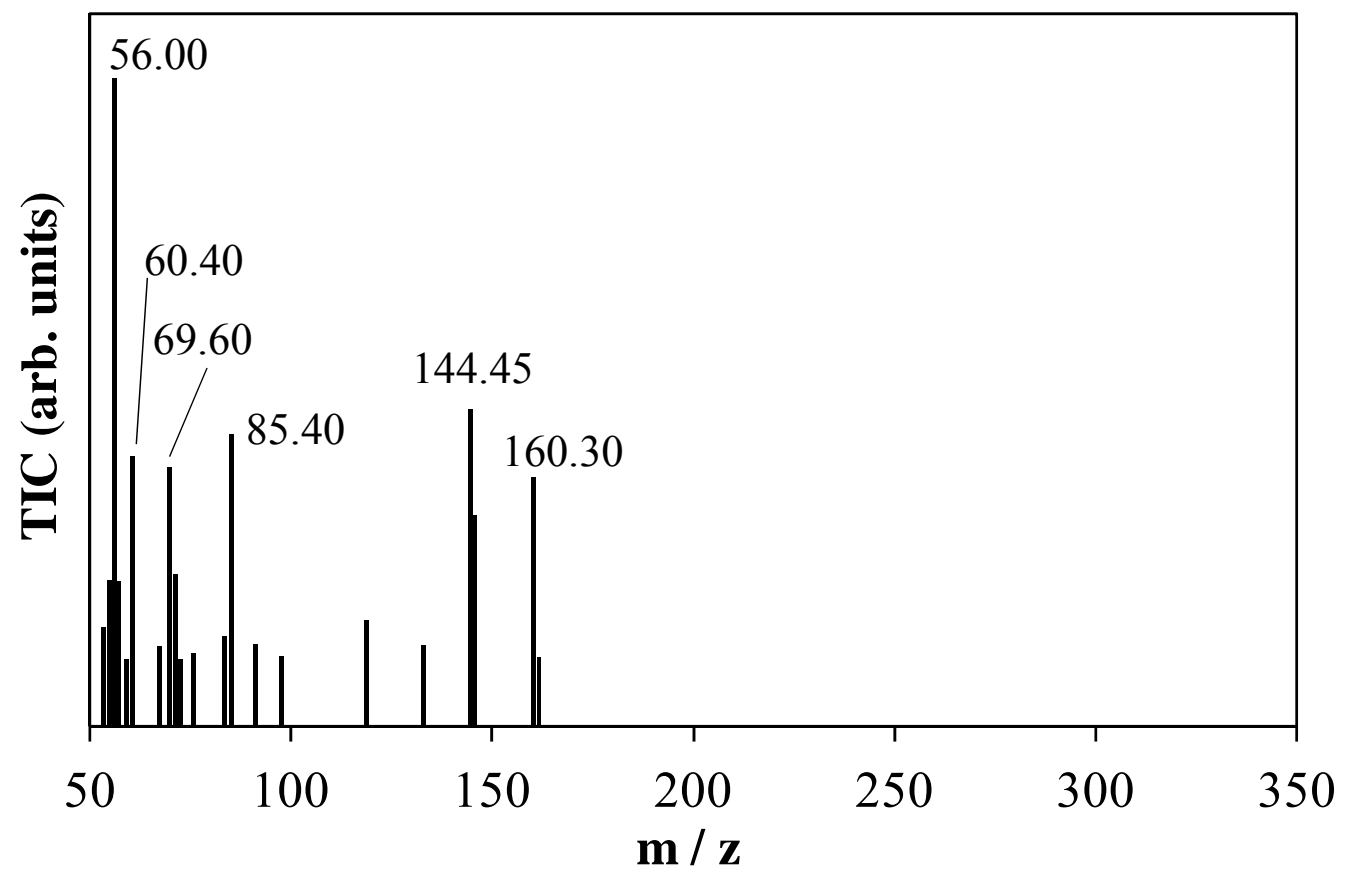

(d)

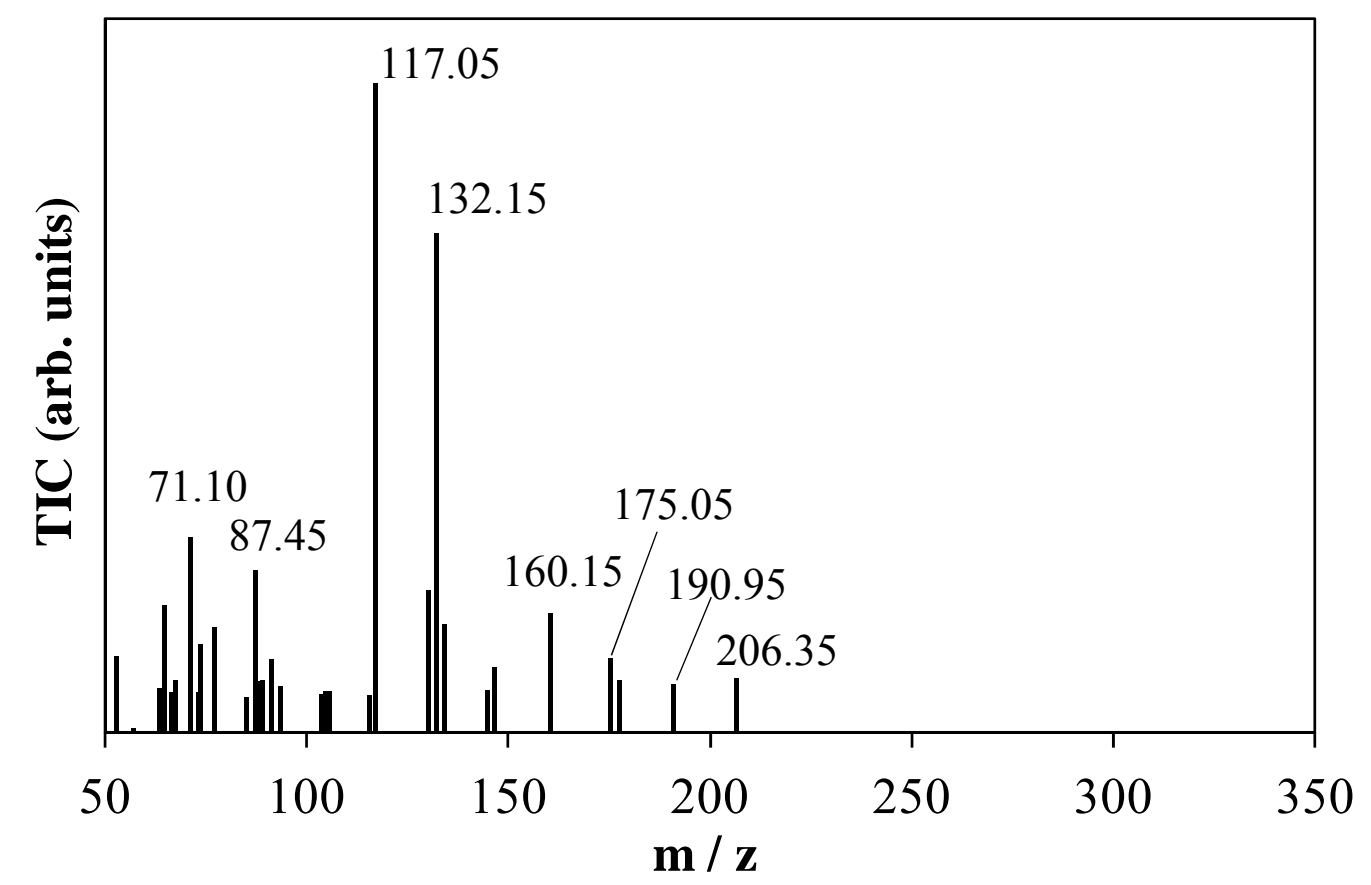


Figure S3 FTIR spectra of (1) the powder prepared from Solution A, and (2) 1-amino-2-naphthol powder.

These spectra are quite similar and some characteristic peaks are observed in both of these spectra. The broad band at $3600-3400 \mathrm{~cm}^{-1}$ indicated the associated $\mathrm{OH}$ stretching vibration. The peaks at 3380 and $3230 \mathrm{~cm}^{-1}$ are assigned to the antisymmetric and symmetric stretching vibrations of $\mathrm{NH}_{2}$, respectively. The sharp peaks at 1656 and 1284 $\mathrm{cm}^{-1}$ should be due to the in-plane bending vibrations of $\mathrm{NH}_{2}$ and $\mathrm{OH}$, respectively. On the other hand, the peak at $1737 \mathrm{~cm}^{-1}$ is only observed in the spectrum of the powder prepared from Solution A. This peak wavenumber should be somewhat different from that of 1,3,3-trimethyloxindole known as a photooxidized product because the $\mathrm{C}=\mathrm{O}$ peak of oxindole was observed at $1697 \mathrm{~cm}^{-1}$. The peak for this powder sample can be assigned to the $\mathrm{C}=\mathrm{O}$ stretching vibration of the carboxyl group, which exhibits a peak at a higher wavenumber. It was confirmed that the $\mathrm{C}=\mathrm{O}$ vibrational energy of the indoline and indole carboxyl acids was higher than that of the ketone and aldehyde compounds by the DFT method (B3LYP). The characteristic peaks of the indoline compound were not found in the spectrum of the powder prepared from Solution A because their main peaks were close to those of 1-amono-2-naphthol. However, it is presumed that the indoline compound contained a 
carboxyl group. The molecular weight of 1,3,3-trimethylindoline carboxylic acid is 205 .

The mass peak, 206.35, shown in Fig. S2(d) was due to the protonated species of this compound. 
Figure S3

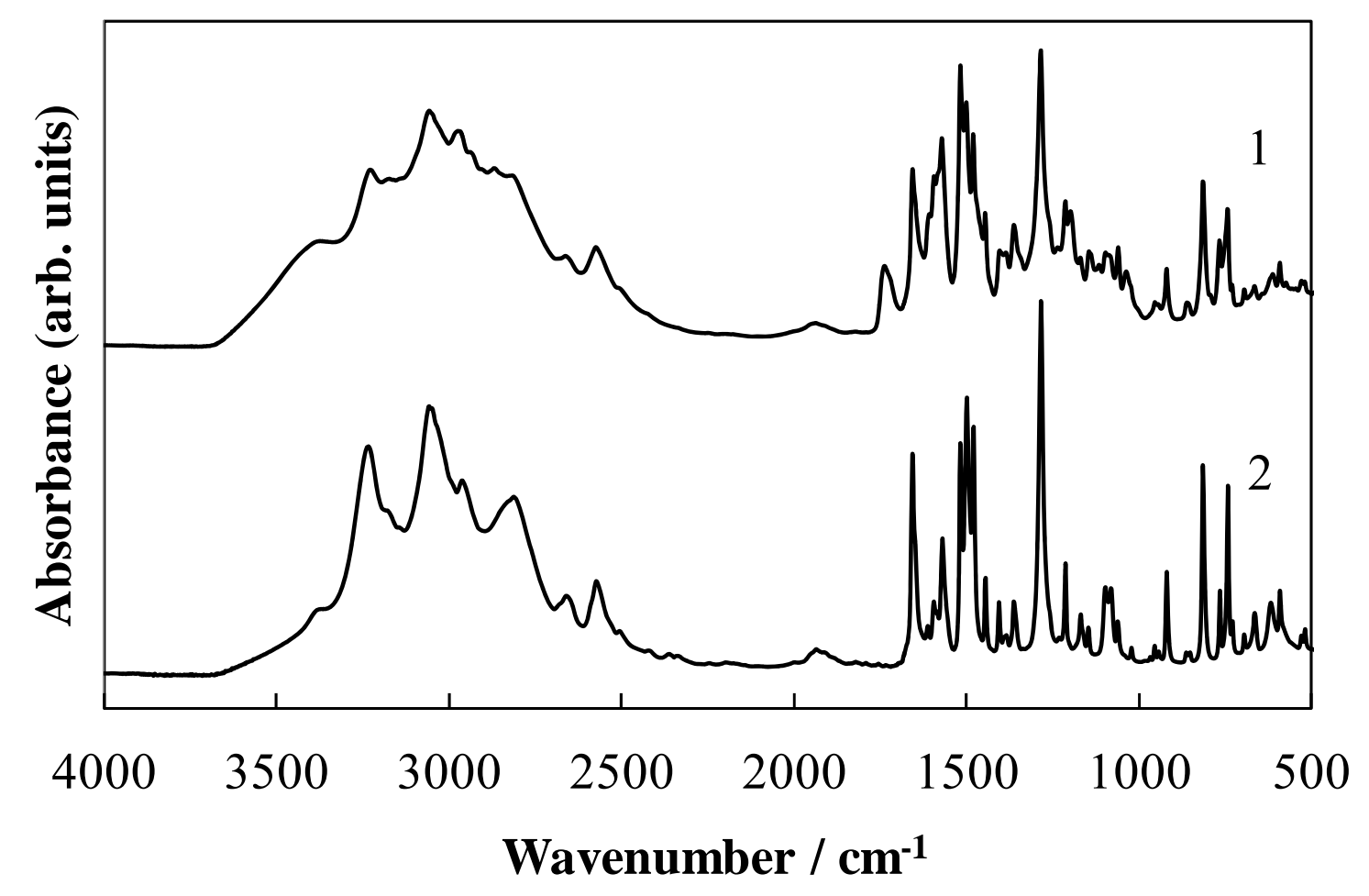

